Doctoral Thesis

\title{
Surface state assisted charge transfer and recombination processes at the semiconductor/electrolyte interface
}

Author:

Luca Bertoluzzi

SUPERVISORS:

Juan Bisquert Mascarell

Sixto Giménez Juliá
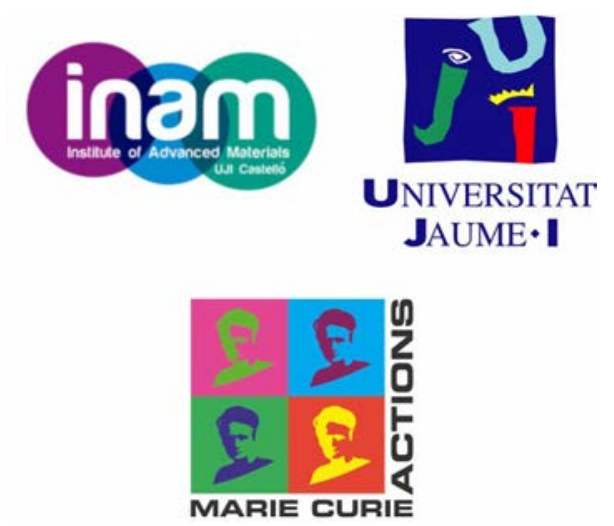

Physics Department

Jaume I University

Castelló de la Plana, Spain

April 2016 

À tous ceux que j'aime 



\section{Acknowledgements}

First of all, I would like to testify all my gratitude to Prof. Juan Bisquert, whom I have been working with for four years, during my master internship and $\mathrm{PhD}$. His great expertise in device modeling and electrochemical characterization techniques such as impedance spectroscopy have allowed me to getting a solid knowledge in the field of photovoltaics and photoelectrochemistry. Our scientific discussion have always been very insightful and creative. We have taken great pleasure in solving complex problems together. I am very thankful to the great professional relationship we have had over these years.

I am also very grateful to my co-director Dr. Sixto Gimenez for the very interesting conversations we have had on the experimental aspects of the electrochemical techniques I have used in this Thesis. Sixto has given me very good advise for the design of useful experiments and has shown great interest in helping me during my $\mathrm{PhD}$.

I also want to sincerely acknowledge Dr. Francisco Fabregat whom I have had exciting conversations with and who has helped me quite a bit with the administrative and organizational part of my $\mathrm{PhD}$. And of course I will always remember our diners in Castellón or abroad.

I am particularly grateful to Prof. Alison Walker from Bath University (UK) and the Marie Curie project DESTINY for funding my PhD. Alison has been coordinating this project with great professionalism and has been very motherly to all the DESTINY fellows. This $\mathrm{PhD}$ would not have been as exciting without her coordination.

I am much obliged to Prof. Raphaël Clerc and Prof. Aldo Di Carlo for all their help and support. In addition to their great classes, they have given me very useful advise in order to build my career project and have introduced me to the world of scientific research. More generally, I want to acknowledge all the professors who have contributed to my academic formation and who have dedicated a lot of time to teaching in the best way they could. 
I am very thankful as well to Prof. Annabella Selloni, Prof. Arie Zaban, Barry Breen and Dr. Fabio Sacconi for welcoming me in their respective group/company and actively participate in my formation. All my research stays have been extremely interesting and exciting.

My acknowledgments are also dedicated to my whole family who has always supported me with joy and love. In particular my parents who have had the patience to raise me. Also, I want to thank my two brothers ("les deux tâches") who have always reminded me that doing advanced studies does not make you more respectable.

Mes remerciements sont aussi dédiés à toute ma famille pour m'avoir toujours soutenu avec joie et amour. Un merci tout particulier à mes parents qui ont eu la patience de m'élever pendant toutes ces années. Je souhaiterais aussi remercier mes deux frères ("les deux tâches") qui m'ont toujours rappelé que faire des études ne rend pas pour autant une personne plus respectable.

A particularly warm thank you goes to my soulmate, better known by my friends and colleagues as "Chéri". Both of us have gone through the tears and joys of this event of life called $\mathrm{PhD}$, and thanks to him I have had more joys than tears.

I also want to acknowledge all my friends who have always stood by me and my colleagues whom I have spent memorable moments with. I have had great scientific conversations with some of my colleagues who have allowed me to making the connection between the mathematical world and the experimental reality.

Finally I am very appreciative of Alexandre Coste for making the cover of this Thesis and Dr. Isaac Herraiz for correcting the Spanish part of this Thesis. 


\section{List of publications}

\section{Publications included in this Thesis}

1. Juan Bisquert, Peter Cendula, Luca Bertoluzzi, Sixto Gimenez. Energy Diagram of Semiconductor/Electrolyte Junctions, The Journal of Physical Chemistry Letters, 2013, 5, 205-207.

2. Luca Bertoluzzi, Juan Bisquert. Equivalent Circuit of Electrons and Holes in Thin Semiconductor Films for Photoelectrochemical Water Splitting Applications, Journal of Physical Chemistry Letters, 2012, 3, 2517-2522.

3. Luca Bertoluzzi, Laura Badia-Bou, Francisco Fabregat-Santiago, Sixto Gimenez, Juan Bisquert. Interpretation of Cyclic Voltammetry Measurements of Thin Semiconductor Films for Solar Fuel Applications, Journal of Physical Chemistry Letters, 2013, 4, 1334-1339.

4. Luca Bertoluzzi, Isaac Herraiz-Cardona, Ronen Gottesman, Arie Zaban, Juan Bisquert. Relaxation of Electron Carriers in the Density of States of Nanocrystalline $\mathrm{TiO}_{2}$, Journal of Physical Chemistry Letters, 2014, 5, 689-694.

5. Luca Bertoluzzi, Pablo P. Boix, Ivan Mora-Sero, Juan Bisquert. Theory of Impedance Spectroscopy of Ambipolar Solar Cells with TrapMediated Recombination, The Journal of Physical Chemistry C, 2013, $118,16574-16580$.

6. Luca Bertoluzzi, Pilar Lopez Varo, Juan Antonio Jimenez Tejada, Juan Bisquert. Charge Transfer Processes at the Semiconductor /Electrolyte Interface for Solar Fuel Production: Insight from Impedance Spectroscopy, Journal of Materials Chemistry A, 2016, 4, 2873 - 2879 


\section{Publications not included in this Thesis}

1. Luca Bertoluzzi and Shuai Ma. On the Methods of Calculation of the Charge Collection Efficiency of Dye Sensitized Solar Cells, Physical Chemistry Chemical Physics, 2013, 15, 4283-4285.

2. Ivan Mora-Sero, Luca Bertoluzzi, Victoria Gonzalez-Pedro, Sixto Gimenez, Francisco Fabregat-Santiago, Kyle W. Kemp, Edward H. Sargent, Juan Bisquert. Selective Contacts Drive Charge Extraction in Quantum Dot Solids via Asymmetry in Carrier Transfer Kinetics, Nature Communications, 2013, 4 .

3. Marta Haro, Taeseup Song, Antonio Guerrero, Luca Bertoluzzi, Juan Bisquert, Ungyu Paik, Germa Garcia-Belmonte. Germanium Coating Boosts Lithium Uptake in Si Nanotube Battery Anodes, Physical Chemistry Chemical Physics, 2014, 16, 17930-17935.

4. Juan Bisquert, Luca Bertoluzzi, Ivan Mora-Sero, Germa Garcia Belmonte. Theory of Impedance and Capacitance Spectroscopy of Solar Cells with Dielectric Relaxation, Drift-Diffusion Transport, and Recombination, Journal of Physical Chemistry C, 2014, 118, 1898318991.

5. Luca Bertoluzzi, Rafael S. Sanchez, Linfeng Liu, Jin-Wook Lee, Elena Mas-Marza, Hongwei Han, Nam-Gyu Park,Ivan Mora-Sero, Juan Bisquert. Cooperative Kinetics of Depolarization in $\mathrm{CH}_{3} \mathrm{NH}_{3} \mathrm{PbI}_{3}$ Perovskite Solar Cells, Energy \& Environmental Science, 2015, 8, 910915.

6. Luca Bertoluzzi. Light Induced Structural Changes in $\mathrm{CH}_{3} \mathrm{NH}_{3} \mathrm{PbI}_{3}$ Perovskite Solar Cells, Journal of Physics Conference Series, 2015, 609, 012001-012005.

7. Koushik Majhi, Luca Bertoluzzi, Kevin James Rietwyk, Adam Ginsburg, David A. Keller, Pilar Lopez-Varo, Assaf Y. Anderson, Juan Bisquert, Arie Zaban. Combinatorial Investigation and Modelling of $\mathrm{MoO}_{3}$ Hole-Selective Contact in $\mathrm{TiO}_{2}-\mathrm{Co}_{3} \mathrm{O}_{4}-\mathrm{MoO}_{3}$ All-Oxide Solar Cells, Advanced Materials Interfaces, 2016, DOI: 10.1002/ admi. 201500405.

8. Xinjian Shi, Isaac Herraiz-Cardona, Luca Bertoluzzi, Pilar Lopez Varo, Juan Bisquert, Jong Hyeok Park, Sixto Gimenez. Understanding the Synergistic Effect of $\mathrm{WO}_{3}-\mathrm{BiVO}_{4}$ Heterostructures by Impedance Spectroscopy, 2016, 18, 9255-9261 
9. Juan Bisquert, Sixto Gimenez, Luca Bertoluzzi, Isaac Herraiz-Cardona. Analysis of Photoelectrochemical Systems by Impedance Spectroscopy, in Photoelectrochemical Solar Fuel Production: From Basic Principles to Advanced Devices, Sixto Gimenez and Juan Bisquert, Springer International Publishing, 2016.

10. Koushik Majhi, Luca Bertoluzzi, David A. Keller, Hannah Barad, Adam Ginsburg, Assaf Y. Anderson, Rosario Vidal, Pilar Lopez-Varo, Ivan Mora-Sero, Juan Bisquert, Arie Zaban. $\mathrm{Co}_{3} \mathrm{O}_{4}$ based All-oxidePV: A Numerical Simulation Analyzed Combinatorial Material Science Study, Journal of Physical Chemistry C, 2016, just accepted 



\section{Resumen}

La necesidad urgente de adoptar las medidas necesarias para limitar el aumento de la temperatura global del planeta a un máximo de $1.5^{\circ} \mathrm{C}$ fue enfatizada durante la Cumbre de París contra el cambio climático celebrada a finales de 2015. En particular, se reconoció "la necesidad de promover el acceso universal a las energías sostenibles, especialmente en África, a través de una mejor implementación de las energías renovables". ${ }^{1}$ La energía solar es, sin duda, la mejor candidata, dado que el Sol constituye la fuente de energía más abundante y accesible a nivel mundial. El principal inconveniente de este tipo de fuente de energía es su carácter diurno. Consecuentemente, para hacer frente a una crisis energética cada vez más preocupante, es fundamental resolver dos retos importantes: la transformación de energía solar en energía útil, y su almacenamiento. Una solución prometedora consiste en el uso de células fotoelectroquímicas que, basadas en la actividad de materiales semiconductores, permiten producir y almacenar energía solar a través de la interfase semiconductor/electrolito. ${ }^{2}$ Con la finalidad de que el proceso sea económicamente competitivo y respete el medio ambiente, es necesario el empleo de materiales presentes en abundancia en la Tierra, lo que supone un bajo coste, no contaminantes, y con una adecuada durabilidad en condiciones de operación. Atendiendo a estos criterios, generalmente se utilizan óxidos metálicos como $\mathrm{TiO}_{2}, \mathrm{Fe}_{2} \mathrm{O}_{3}, \mathrm{ZnO}, \mathrm{WO}_{3}, \mathrm{BiVO}_{4}$, etc. Desafortunadamente, dichos materiales presentan una gran densidad de defectos que pueden afectar negativamente a la actividad fotoelectroquímica. Por tanto, la investigación en este campo se centra en la optimización de los dispositivos fotoelectroquímicos siguiendo dos tipos de estrategias: el uso de capas protectoras para pasivar tales defectos, y catalizadores que aceleren los procesos de transferencia de carga que intervienen en la transformación de la energía solar en energía química. ${ }^{3}$ Sin embargo, surge la siguiente pregunta: ¿cuál es la interacción entre los defectos y los procesos que gobiernan la fotocorriente? En este ámbito, la presente Tesis Doctoral aborda retos de gran importancia y plantea métodos nuevos para la mejora de la actividad fotoelectroquímica, tal como se detalla a continuación. 
-Origen de la fotocorriente. El origen de la fotocorriente está bien caracterizado en células fotoelectroquímicas, como las células solares de colorante o de puntos cuánticos, donde el transporte electrónico está separado de la fotogeneración. ${ }^{4}$ En este caso, los electrones fotogenerados se inyectan en el substrato y el transporte electrónico está asegurado por un único portador. Para este tipo de sistemas, la corriente de recombinación proviene de procesos de recombinación localizados en la interfase semiconductor/electrolito. Se han identificado dos tipos de procesos: transferencia de carga directa desde la banda de conducción (en el caso de un semiconductor tipo n), o transferencia indirecta desde estados localizados en la interfase semiconductor/electrolito. La cinética de dichos procesos se puede cuantificar con varios métodos en régimen dinámico. Un ejemplo ampliamente empleado es la técnica de espectroscopia de impedancia. Sin embargo, en el caso de células fotoelectroquímicas como las utilizadas para la producción de combustibles solares, tanto la fotogeneración como el transporte electrónico ocurren en el mismo material. En este caso, intervienen nuevos procesos de recombinación. En primer lugar, los huecos atrapados en los estados localizados en la interfase semiconductor/electrolito pueden recombinar con los electrones atrapados o transferirse al electrolito (por reacción química), tal y como sugirieron Kelly y Memming. ${ }^{5}$ Además, la transferencia de carga en la interfase semiconductor/electrolito puede estar afectada por la recombinación interna. Debido a esto, las herramientas de caracterización actuales no permiten distinguir los diferentes procesos de recombinación y de transferencia de carga, lo cual limita la optimización de la fotocorriente en este tipo de dispositivos. En esta Tesis Doctoral, se ha propuesto por primera vez un método que permite distinguir entre los diferentes procesos de recombinación y transferencia de carga previamente mencionados. El método propuesto se basa en un circuito eléctrico equivalente general, desarrollado con la técnica de espectroscopia de impedancia. $\mathrm{Al}$ analizar la capacidad química de baja frecuencia se demuestra que es posible distinguir entre los procesos de transferencia de carga directa e indirecta en los electrodos usados para la producción de combustible solar (es decir, en presencia de electrones y huecos). Estos resultados contribuyen de manera significativa al conocimiento de los procesos que limitan la eficiencia de estos dispositivos, y son esenciales en la elección de catalizadores y capas protectoras adecuados.

-Papel de los estados superficiales en la producción de fotocorriente. En los modelos fotoelectroquímicos clásicos, los estados superficiales se consideran centros de recombinación de electrones y huecos que inducen pérdidas de fotocorriente. Además, en el modelo clásico de la bar- 
rera Schottky, generalmente no se tiene en cuenta la presencia de dichos estados, puesto que en presencia de un campo eléctrico suficiente, la separación de carga se realiza de modo eficiente, y la recombinación en la zona de carga espacial es despreciable. ${ }^{6}$ Mediante simulaciones numéricas avanzadas de transporte electrónico por conducción y difusión se demuestra por primera vez que los estados localizados en la interfase semiconductor/electrolito pueden ser beneficiosos para la producción de combustibles solares. Adicionalmente, en presencia de un campo eléctrico, la recombinación de electrones y huecos en estos estados disminuye de manera considerable, lo que induce una mejora de la transferencia de carga desde los mismos. Este estudio tiene una importancia singular, ya que demuestra un nuevo papel de los estados superficiales en la producción de fotocorriente, contrario a lo que afirman los modelos clásicos.

- Naturaleza de los estados superficiales que afectan la interfase semiconductor/electrolito. Existen dos tipos de estados localizados en la interfase semiconductor/electrolito. Los estados intrínsecos, que resultan de una ruptura local de periodicidad del cristal, y los estados extrínsecos, que resultan de la interacción entre la superficie del semiconductor y especies químicas adsorbidas en esta superficie. Estos últimos estados pueden estar influenciados por la historia fotoelectroquímica del fotoelectrodo. Es decir, la aplicación de un voltaje o una iluminación prolongada puede cambiar la densidad de dichos estados y, consecuentemente, los procesos de recombinación y transferencia de carga. Generalmente, se examina la densidad de estados a través de técnicas de vacío ultra-alto. Sin embargo, estas técnicas físicas se realizan ex situ y no en condiciones reales (in situ). Algunas técnicas ópticas y de espectroscopia de rayos $\mathrm{X}$ permiten un análisis de los estados superficiales in situ. No obstante, estos métodos se limitan a casos específicos. ${ }^{7} \mathrm{El}$ análisis de estados superficiales en la interfase semiconductor/electrolito se puede realizar de modo más eficiente mediante técnicas electroquímicas. Hasta ahora, este tipo de análisis se había realizado exclusivamente a nivel cualitativo. Por ejemplo, se demostró, a través de medidas de voltametría cíclica, la presencia de estados extrínsecos transitorios en la superficie del $\mathrm{TiO}_{2}$. En la presente Tesis Doctoral, se presenta un enfoque cuantitativo. ${ }^{8}$ Mediante medidas de voltametría cíclica se demuestra la modulación de la densidad de estados extrínsecos en la interfase $\mathrm{Fe}_{2} \mathrm{O}_{3}$ /electrolito al variar el potencial de pre-tratamiento aplicado y el nivel de iluminación. Combinando estas medidas con un modelo cinético, se analiza también la cinética de atrapamiento en los estados intrínsecos y extrínsecos, y se discute la influencia sobre la recombinación. Finalmente, con estas medidas y el modelo cinético, se verifica también el efecto catalizador del óxido de Iridio, $\mathrm{IrO}_{x}$, depositado sobre electrodos de hematita. 
-Efecto de la morfología del fotoelectrodo. Los estados localizados intrínsecos, previamente mencionados, dependen íntimamente de la morfología del semiconductor. En el caso de electrodos nanoestructurados, el tamaño de grano puede influir sobre la densidad de estados. En el caso de capas continuas, pueden aparecer trampas internas adicionales a la densidad de estados localizados en la interfase semiconductor/electrolito. En ambos casos, la cinética de atrapamiento y la densidad de estados pueden variar. En esta Tesis, se correlacionan cinética de atrapamiento, densidad de estados y morfología. Mediante medidas de voltametría cíclica y un modelo cinético sencillo, se demuestra que el tamaño de nano-partículas de óxido de titanio $\left(\mathrm{TiO}_{2}\right)$ cambia la distribución exponencial de estados localizados en este material. Además, se muestra que el tiempo característico de atrapamiento de los electrones en dichos estados cambia drásticamente, lo cual tiene consecuencias importantes sobre la transferencia de carga en la interfase semiconductor/electrolito y el comportamiento fotoelectroquímico. Finalmente, en otro estudio, se desarrolla un modelo de espectroscopia de impedancia que permite cuantificar la cinética de recombinación interna en capas semiconductoras continuas, en el caso de semiconductores dopados e intrínsecos. Ambos estudios establecen un método eficiente para analizar la dependencia con la morfología del electrodo de la densidad y cinética asociados a estados localizados en semiconductores para aplicaciones fotoelectroquímicas.

\section{References}

1 http://elpais.com/tag/cumbre_del_clima/a/

${ }^{2}$ Gratzel, M. Photoelectrochemical Cells. Nature 2001, 414, 338-344.

${ }^{3}$ Guijarro, N.; Prevot, M. S.; Sivula, K. Surface Modification of Semiconductor Photoelectrodes. Physical Chemistry Chemical Physics, 2015, 17, 15655-15674.

${ }^{4}$ Mora-Sero, I.; Bisquert , J. Breakthroughs in the Development of Semiconductor-Sensitized Solar Cells. PJournal of Physical Chemistry Letters 2010, 1, 0463052.

${ }^{5}$ Kelly, J. J.; Memming, R. The Influence of Surface Recombination and Trapping on the Cathodic Photocurrent at p-Type III-V Electrodes. Journal of the Electrochemical Society, 1982, 192, 730-738.

${ }^{6}$ Cendula, P.; Tilley, S. D.; Gimenez, S.; Bisquert, J.; Schmid, M.; Grtzel, M.; Schumacher, J. O. Calculation of the Energy Band Diagram of a Photoelectrochemical Water Splitting Cell. The Journal of Physical Chemistry C 2014, 118, 29599-29607. 
${ }^{7}$ Jaegermann, W. The Semiconductor/Electrolyte Interface: A Surface Science Approach. Modern Aspects of Electrochemistry; 1996, 30, 1186.

${ }^{8}$ Gutierrez, C.; Salvador, P. Mechanisms of Competitive Photoelectrochemical Oxidation of $\mathrm{I}^{-}$and $\mathrm{H}_{2} \mathrm{O}$ at n- $\mathrm{TiO}_{2}$ Electrodes: A Kinetic Approach. Journal of the Electrochemical Society, 1986, 133, 924-929. 



\section{Contents}

Title i

List of publications vii

Resumen xi

1 Introduction 1

1.1 Solar energy storage at the semiconductor/ electrolyte interface 1

1.1.1 Brief introduction on photovoltaic and photoelectrochemical systems for solar energy storage. . . . . . . . 1

1.1 .2 Semiconductors used for solar fuel production. . . . . 3

1.1 .3 Solar fuel device architecture . . . . . . . . . . . . 4

1.2 Charge transfer at the semiconductor/ electrolyte interface . 6

$1.2 .1 \quad$ Direct charge transfer $\ldots \ldots \ldots 6$

1.2.1.1 Tuning charge transfer kinetics . . . . . . . 6

1.2.1.2 $\quad$ Tuning carrier densities . . . . . . . . . . . . 9

1.2 .2 Influence of surface states . . . . . . . . . . . . 10

1.2 .3 Influence of bulk recombination . . . . . . . . . . . . 14

1.2 .4 Optimization of charge transfer . . . . . . . . . . . 18

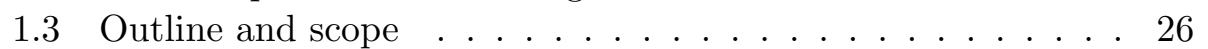

$1.3 .1 \quad$ Formulation of the problem . . . . . . . . . . 26

1.3 .2 Objectives . . . . . . . . . . . . . . 26

1.3 .3 Structure of the Thesis . . . . . . . . . . . . . . . 27

1.4 References . . . . . . . . . . . . . . . . . . . . . . 29

\begin{tabular}{|lll}
2 & Characterization methods and modeling & 35
\end{tabular}

2.1 Modeling framework . . . . . . . . . . . . . . . . 35

$2.1 .1 \quad$ Hypotheses $\ldots \ldots \ldots \ldots \ldots \ldots$

2.1 .2 Reference model . . . . . . . . . . . . . . . 36

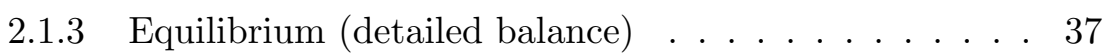

2.1.4 Relation between applied voltage and carrier densities 38

2.2 Steady State: $j V$ curve and dc resistance $\ldots \ldots . \ldots . \ldots 39$

2.3 Impedance spectroscopy $\ldots \ldots \ldots \ldots$. . . . . . . . . 40 
2.4 Cyclic voltammetry . . . . . . . . . . . . . . 46

2.5 References . . . . . . . . . . . . . . . . . . . . . . . . . . 48

$\begin{array}{lll}3 & \text { Publication 1 } & 51\end{array}$

3.1 Candidate's contribution . . . . . . . . . . . . . . . 51

3.2 Published manuscript $\ldots \ldots \ldots \ldots \ldots$. . . . . . . . . 51

4 Publication 2 55

4.1 Candidate's contribution . . . . . . . . . . . . . 55

4.2 Published manuscript . . . . . . . . . . . . . . . 55

5 Publication 3 63

5.1 Candidate's contribution . . . . . . . . . . . . . 63

5.2 Published Manuscript $\ldots \ldots \ldots \ldots$. . . . . . . . . . 63

$\begin{array}{lll}6 & \text { Publication } 4 & 73\end{array}$

6.1 Candidate's contribution . . . . . . . . . . . . . 73

6.2 Published Manuscript $\ldots \ldots \ldots$. . . . . . . . . . 73

\begin{tabular}{llr}
\hline $\mathbf{7}$ & Publication 5 & $\mathbf{8 7}$
\end{tabular}

7.1 Candidate's contribution . . . . . . . . . . . . . . 87

7.2 Published Manuscript . . . . . . . . . . . . . . . . . 87

$\begin{array}{lll}8 & \text { Publication 6 } & 95\end{array}$

8.1 Candidate's contribution . . . . . . . . . . . . . . . 95

8.2 Published Manuscript . . . . . . . . . . . . . . . . . . . 95

9 Discussion of the results 113

10 Conclusiones y futuras líneas de investigación 117 


\section{Introduction}

\subsection{Solar energy storage at the semiconductor/ electrolyte interface}

\subsubsection{Brief introduction on photovoltaic and photoelectro- chemical systems for solar energy storage.}

Limiting the global average temperature increase to $1.5^{\circ} \mathrm{C}$ has been one of the main concerns addressed during the last Summit on climate change in Paris, at the end of 2015. In particular, it was acknowledged "the need to promote universal access to sustainable energy in developing countries, in particular in Africa, through the enhanced deployment of renewable energy". "To such extent, solar energy is considered to be the best candidate because the Sun constitutes the largest abundant source of energy. One problem though is its inconstancy because of its diurnal feature, while our energy demand is permanent. Therefore, in addition to transforming the energy of the Sun, the other current preoccupation is to store it. ${ }^{2}$

A promising alternative can be encountered using photovoltaic (PV) cells immersed in solution, or photoelectrochemical cell (PEC), or any combination of both. PV cells are constituted of solid/solid junction(s) (also named buried junction), while PEC cells are constituted of, at least, a semiconductor/electrolyte junction. Both, PV and PEC cells allow transforming solar energy into electricity or into chemical energy for solar energy production and storage. However, it must be pointed out that energy production by PV cells is much more efficient in dry environment than in solution. In addition, PEC devices for energy production such as dye sensitized solar cells 
(DSCs), ${ }^{3}$ and quantum dot solar cells (QDSCs), ${ }^{4,5}$ have been intensively studied over the past 25 years and further information about the working principles of such cells can be found in ref. ${ }^{6}$ In the following, we mainly focus on solar energy storage at the semiconductor/electrolyte interface.

Solar energy storage can be achieved through solar fuel production. In this case, solar energy is converted into chemical energy through chemical bonds at the semiconductor/electrolyte interface. A popular example is solar water splitting, which was first reported by Fujishima and coworkers in the early 70 s with the use of a titanium oxide based PEC. ${ }^{7}$ Water splitting consists in storing solar energy in dihydrogen and dioxygen molecules by using appropriate semiconductors. The global water splitting reaction is $2 \mathrm{H}_{2} \mathrm{O} \rightarrow \mathrm{O}_{2}+2 \mathrm{H}_{2}$. However this reaction is in reality the sum of two semireactions. In basic environment, these reactions are: (1) reduction of water, also named hydrogen evolution reaction (HER): $2 \mathrm{H}_{2} \mathrm{O}+2 \mathrm{e}^{-} \rightarrow 2 \mathrm{HO}^{-}+\mathrm{H}_{2}$ and (2) oxidation of water, also called oxygen evolution reaction (OER): $4 \mathrm{HO}^{-}+4 \mathrm{~h}^{+} \rightarrow 2 \mathrm{H}_{2} \mathrm{O}+\mathrm{O}_{2}$.

(a)

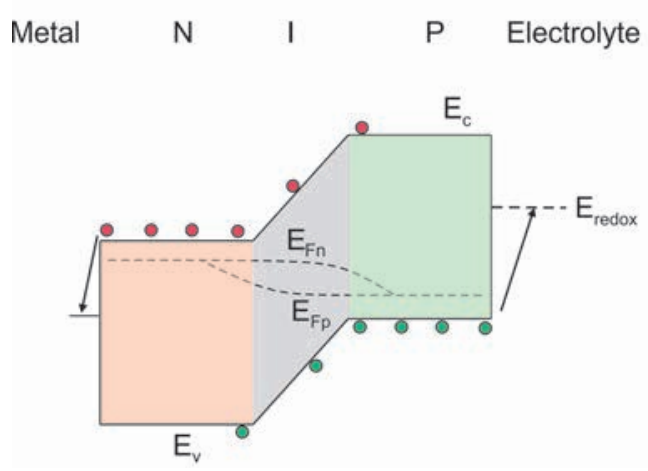

(b)

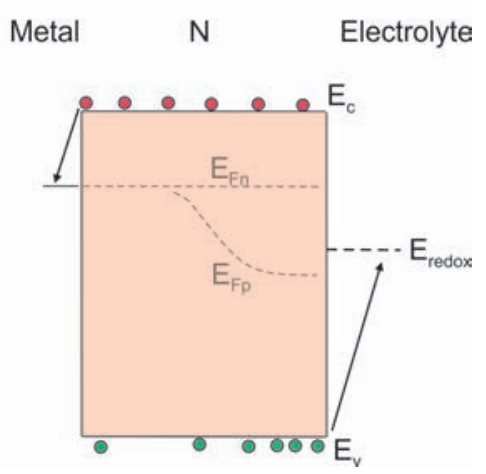

Figure 1.1: Energy diagram of (a) a burried PIN junction (PV cell) where the maximum achievable photovoltage and photocurrent arise from Fermi level splitting within the illuminated junction, and are independent of the semiconductor/electrolyte interface, and (b) an n-type semiconductor (PEC cell) where photovoltage and photocurrent both depend on the nature of the semiconductor/electrolyte interface. The holes involved in the oxidation reaction are majority carriers in the first case and minority carriers in the second one. N, I and P refer to n-type, intrinsic and p-type semiconductors, respectively, while $E_{F n}, E_{F p}$ are the electron and hole quasi Fermi levels, and $E_{c}$ and $E_{v}$ are the semiconductor conduction and valence bands.

More generally, solar fuel production is based on two types of electrochemical reactions: reduction and oxidation of species in the electrolyte. Such reactions can be performed either by PV or PEC cells. The main 
1.1. Solar energy storage at the semiconductor/ electrolyte interface

difference between both systems is the origin of the photovoltage and photocurrent which give rise to solar fuels production, as shown in Figure 1.1. In PV systems, which are based on a buried junction, both the photovoltage and photocurrent arise from the separation of the quasi Fermi levels within the solid semiconductor junction. In this case, the maximum achievable photovoltage and photocurrent are both independent of the nature of the semiconductor/electrolyte interface, and the chemical reactions leading to solar fuel production involve majority carriers. For example, in Figure 1.1 a, a buried NIP junction is formed and holes from the p-type semiconductor, in contact with the electrolyte, perform the oxidation reaction. On the contrary, for a PEC cell, both photocurrent and photovoltage are governed by the difference in electrochemical levels between the semiconductor and the electrolyte, as well as the charge transfer kinetic at the semiconductor/electrolyte interface. In addition the chemical reactions leading to solar fuel production involve minority carriers. For example, in Figure $1.1 \mathrm{~b}$, the photogenerated minority carriers in an n-type semiconductor (holes) are involved in the oxidation reaction.

\subsubsection{Semiconductors used for solar fuel production.}

Semiconductors used in PEC or PV cells for solar fuel production must fulfill several conditions, ${ }^{8}$ which are summarized hereafter:

- Low cost: materials must be Earth abundant so that they ensure low and competitive device cost for commercialization. In the case of PEC systems, material processing can be simple and cheap, especially when using metal oxides, or solution processed heterojunctions. On the contrary, low cost materials and fabrication methods for PV systems immersed in solution is one of the current challenges that material scientists are facing.

- Green chemistry in order to avoid environmental pollution.

- Robustness of the materials in solution for long term device stability. This is certainly one of the most challenging issues that both, PEC and PV cells, must overcome. In the case of PV systems, which are usually operational in dry conditions, this implies the discovery of transparent and conductive protective layers.

- Suitable optoelectronic properties. This includes absorption in the visible region of the solar spectrum, where the photon flux is the most intense. In addition, the band position must be adequate so that the 
thermodynamics of the oxidation and reduction reactions is favored. ${ }^{9}$ In fact, the conduction band must be situated above the redox level for the reduction reaction to occur, while the valence band must be situated below the redox level for the oxidation reaction to take place. In the case of water splitting, the semiconductor band gap must be superior to $1.23 \mathrm{eV}$, which corresponds to the energy difference between the two redox levels of water $\left(\mathrm{O}_{2} / \mathrm{H}_{2} \mathrm{O}\right.$ and $\left.\mathrm{H}_{2} \mathrm{O} / \mathrm{H}_{2}\right)$ in standard conditions of pressure and temperature.

- Suitable kinetics of charge transfer at the semiconductor/electrolyte interface. This criterion is especially valid for PEC systems. In fact, even though the semiconductor bands "straddle" the redox energy levels, charge extraction is kinetically limited and overvoltages must be applied for solar fuel production to take place. ${ }^{10}$ For instance, in the case of water splitting, the OER reaction constitutes the bottleneck of the overall reaction since four holes are required, instead of the two electrons required for the HER reaction. This is what limits the application to water splitting of widely used materials such as $\mathrm{TiO}_{2},{ }^{11} \mathrm{BiVO}_{4},{ }^{12} \mathrm{WO}_{3},{ }^{13}$ and $\mathrm{Fe}_{2} \mathrm{O}_{3},{ }^{14,15}$ in spite of their significant assets in terms of stability and suitable energetics for the water oxidation reaction. In addition, slow charge transfer kinetics at the semiconductor/electrolyte interface can also decrease the value of the photovoltage and photocurrent in PV systems.

\subsubsection{Solar fuel device architecture}

The solar to chemical power conversion efficiency, $\eta$, is determined by the potential difference $\Delta V_{\text {redox }}$ between the redox levels, the operational current, $J_{o p}$, and the incident irradiance, $P_{i n}$. For solar water splitting, $\Delta V_{\text {redox }}$ value is $1.23 \mathrm{~V}$, and the solar to hydrogen ( $\mathrm{STH}$ ) conversion efficiency is given by the following equation: ${ }^{16}$

$$
\eta=\frac{1.23 J_{o p}}{P_{\text {in }}}
$$

The STH for water splitting with devices composed of one single junction (PV or PEC cells) is low $(<1 \%)$. In fact, such device are more appropriate for fuel production reactions which require applied voltages inferior to $1 \mathrm{~V}$. It is therefore convenient to boost device performance by resorting to multiple junctions and/or using catalysts. As such, double (2J) and triple (3J) junction devices have been reported to give efficiencies superior to $10 \%$, Figure 1.2, when catalysts are directly deposited on the photoelectrode(s) (integrated devices) or wired to it. ${ }^{17}$ 


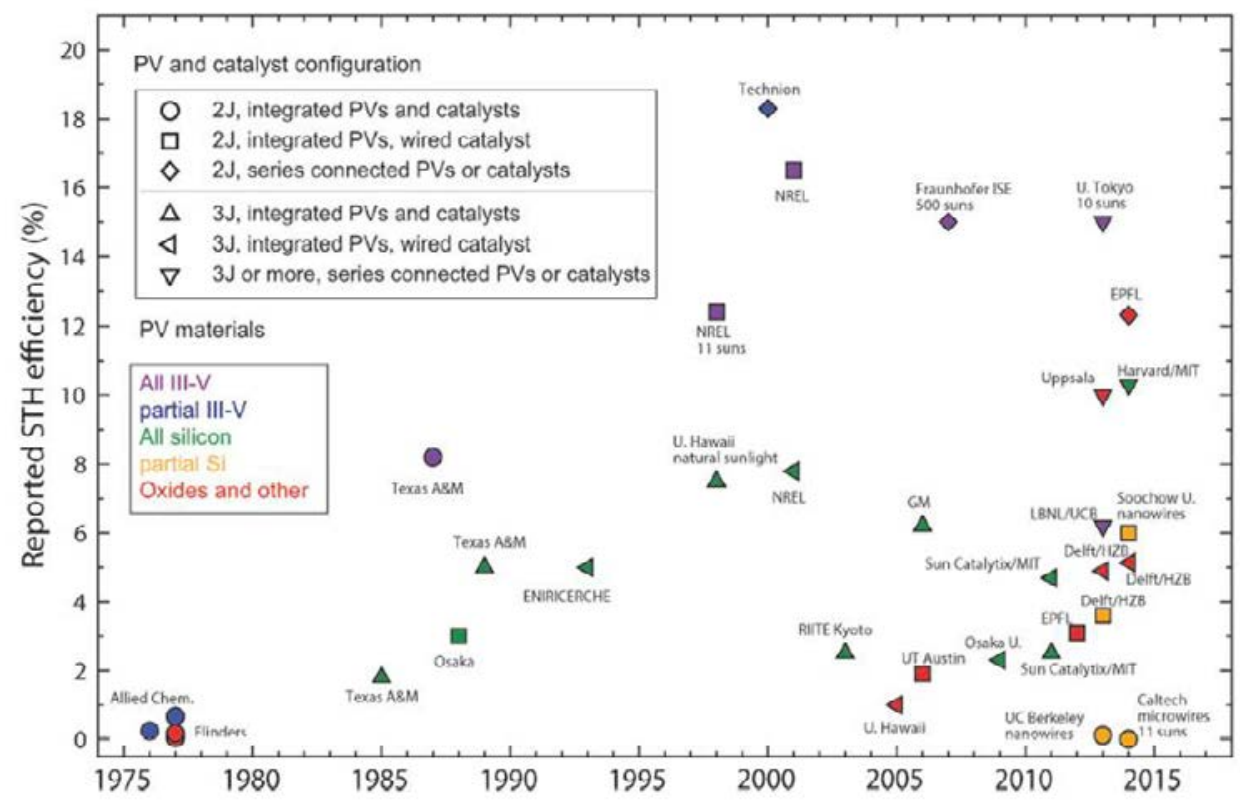

Figure 1.2: Reported solar to hydrogen (STH) conversion efficiencies as a function of year and sorted by the number of tandem photovoltaic junctions used (2 or 3 ). The degree of integration of photovoltaic and catalyst elements is also distinguished. The fill color represents the semiconductor materials used in the photovoltaic portion of the device. All STH conversion efficiencies are as reported in the original publications. Reproduced from ref. 17 with permission of The Royal Society of Chemistry.

Two categories of multiple junction devices can be distinguished: "photoelectrosynthetic" cells, which use at least one semiconductor/electrolyte junction, and "photovoltaic-biased electrosynthetic" cells which use solid/ solid junctions. ${ }^{18}$ Nonetheless, it must be emphasized that this Thesis focuses on the characterization of the semiconductor/electrolyte interface in single PEC junctions, such as the one shown in Figure 1.1b. However, the results obtained throughout this $\mathrm{PhD}$ can be extended to multiple junction devices of the photoelectrosynthetic type. 


\subsection{Charge transfer at the semiconductor/ elec- trolyte interface}

\subsubsection{Direct charge transfer}

From the previous considerations, it is clear that enhancement of the charge transfer kinetics at the semiconductor/electrolyte is crucial for the optimization of solar fuel production via PEC cells. In particular, only one type of photogenerated carrier should be transferred to the solution, depending on the electrode function. For instance, in the case of a photoanode, electron transfer from the conduction band must be as low as possible while hole transfer from the valence band must be maximized. ${ }^{19}$

The electronic current resulting from direct charge transfer from the conduction $\left(\mathrm{j}_{c t}^{c b}\right)$ / valence band $\left(\mathrm{j}_{c t}^{v b}\right)$ at the semiconductor/electrolyte interface depends on the density of carriers ( $n$ for electrons and $p$ for holes), the concentration of acceptors in the electrolyte $\left(c_{o x}\right.$ for the cations and $c_{\text {red }}$ for the anions), and the charge transfer kinetics from the conduction band $\left(\nu_{e l}^{c b}\right) /$ valence band $\left(\nu_{e l}^{v b}\right)$ :

$$
\begin{gathered}
j_{c t}^{c b}=q n \nu_{e l}^{c b} c_{o x} \\
j_{c t}^{v b}=q p \nu_{e l}^{v b} c_{r e d}
\end{gathered}
$$

Where $q$ is the elementary charge. Note that the concentrations of acceptors in the electrolyte are far superior to the concentration of free carriers in the semiconductor and are supposed to be invariant upon application of an external voltage bias and/or illumination. We therefore neglect diffusion limited currents. We shall now discuss the influence of charge transfer kinetics and electronic carrier concentration on the current of charge transfer. Note that in this section the effect of recombination and transport processes are not introduced. For the sake of concision, we consider only the case of photoanodes used for solar fuel applications. However the following considerations can be easily adapted to photocathodes.

\subsubsection{Tuning charge transfer kinetics}

The first parameters that can be tuned to optimize the direct charge transfer currents given Equation 1.2 are the charge transfer kinetics $\nu_{e l}^{c b}$ and $\nu_{e l}^{v b}$. Such parameters are treated in the framework of the semi-classical kinetic theory of charge transfer, initially developed by Marcus. ${ }^{20}$ This theory 
embraces various cases, such as charge transfer between molecular systems, at metal and semiconductor electrodes and liquid interfaces. However, for the purpose of this Thesis, we first summarize briefly the main concepts underlying the theory of charge transfer between acceptor and donor states and subsequently discuss the main results of the Marcus theory applied to the semiconductor/electrolyte interface. It should be pointed out that the piece of theory we introduce here is limited to the case of the outer sphere electron transfer reactions, in which the system does not undergo significant structural modifications.

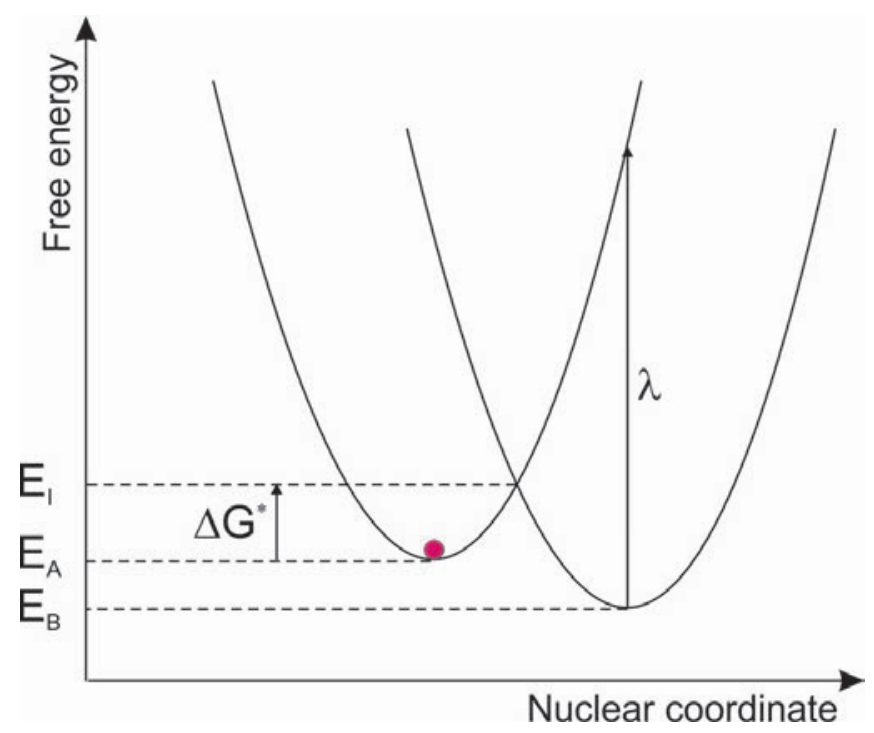

Figure 1.3: Free energy plot as a function of nuclear coordinate for a state $A$ with energy $E_{A}$ and a state $B$ with energy $E_{B}$. Energy conservation and Frank-Condon principles impose that an electron can transfer from $\mathrm{A}$ to $\mathrm{B}$ only if it reaches an intermediate state I with energy $E_{I}$ such that $E_{A}=E_{B}$. This is equivalent to say that the electron must overcome a free energy barrier $\Delta G^{*} . \Delta G^{*}$ depends on the the reorganization energy $\lambda$.

In Figure 1.3, we consider charge transfer from a state $A$ with energy $E_{A}$ to a state $B$ with energy $E_{B}$. For such process to occur, the conservation of energy must be respected before and after the jump of the electron. This condition must be achieved by reorganization of the solvent molecule around the molecule/ion during charge transfer. However, according to the Frank-Condon principle the nuclei can be considered motionless with respect to the electrons involved in the electronic transfer. As a result, the nuclei do not have time to adjust their position and momentum during such process. The only possibility invoked in Marcus theory is therefore a prior modification of the vibration and polarization modes by thermal fluctuation 
of the solvent molecules around the ion/molecule where charge transfer will take place. ${ }^{21,22}$ This suggests that an intermediate state $I$ with energy $E_{I}$ has to be reached in which the energy of the system before and after the jump is equal. In other words, the electron has to overcome the free energy barrier, $\Delta G^{*}=E_{I}-E_{A}$, between states $A$ and $I . \Delta G^{*}$ is determined by the energy barrier between the initial and final states $\left(E_{B}-E_{A}\right)$ and the reorganization energy, $\lambda$. In addition, the probability for an electron from state I to reach B depends on the coupling between the semiconductor and the oxidized redox species via the effective coupling length and the coupling attenuation factors. It also depends on the density of atoms that contribute to the density of states of concern (atoms or surface states). Within this conceptual framework, the rate of electron transfer from A to B can be written as: ${ }^{23}$

$$
\nu_{e l}=A_{e l} \exp \left(-\frac{\left(E_{B}-E_{A}+\lambda\right)^{2}}{4 \lambda k_{B} T}\right)
$$

Where $A_{e l}$ depends on the probability of electron tunneling from I to B. These concepts can be generalized to the case of the semiconductor/electrolyte interface. ${ }^{24}$ Equation 1.3 can be applied to the kinetics of electronic charge transfer between the redox level $E_{\text {redox }}$ and the conduction band, $E_{c}$, and valence band, $E_{v}$ :

$$
\begin{aligned}
& \nu_{e l}^{c b}=A_{e l}^{c b} \exp \left(-\frac{\left(E_{c}-\left(E_{r e d o x}+\lambda\right)\right)^{2}}{4 \lambda k_{B} T}\right) \\
& \nu_{e l}^{v b}=A_{e l}^{v b} \exp \left(-\frac{\left(E_{v}-\left(E_{r e d o x}-\lambda\right)\right)^{2}}{4 \lambda k_{B} T}\right)
\end{aligned}
$$

It should be remarked that at equilibrium $E_{\text {redox }}=E_{F 0}, E_{F 0}$ being the equilibrium Fermi level of the semiconductor. In addition it must be noted that the charge transfer rates of Equations 1.4a and 1.4b are independent on the applied voltage or illumination. In order to understand how these kinetic rates can be engineered to optimize the overall charge transfer process, it is useful to resort to the classical Gaussian representation depicted in Figure 1.4. In this representation, the electron transfer probability (the exponential term in Equations 1.4a and 1.4b is a Gaussian centered in $E_{\text {redox }}+\lambda$ with variance $\sqrt{\lambda k_{b} T}$, and electron transfer is all the more probable as the conduction band is closer to the center of the Gaussian. Away from the Gaussian center, electronic charge transfer becomes less probable. Similarly, the hole transfer probability can be represented with a Gaussian centered in $E_{\text {redox }}-\lambda$ with variance $\sqrt{\lambda k_{b} T}$ and hole transfer reaches its highest probability when the valence band coincides with the center of the Gaussian. 
(a)

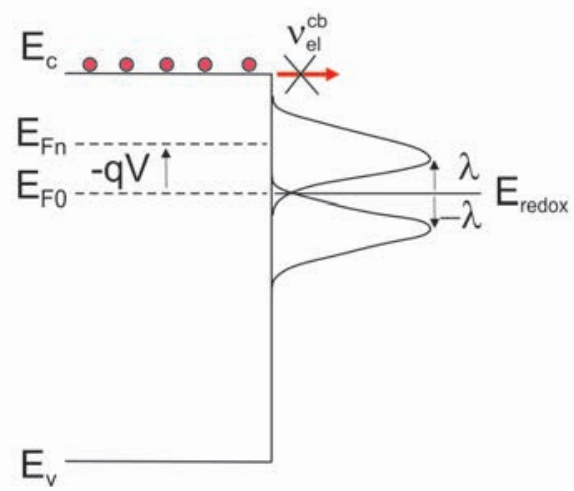

(b)

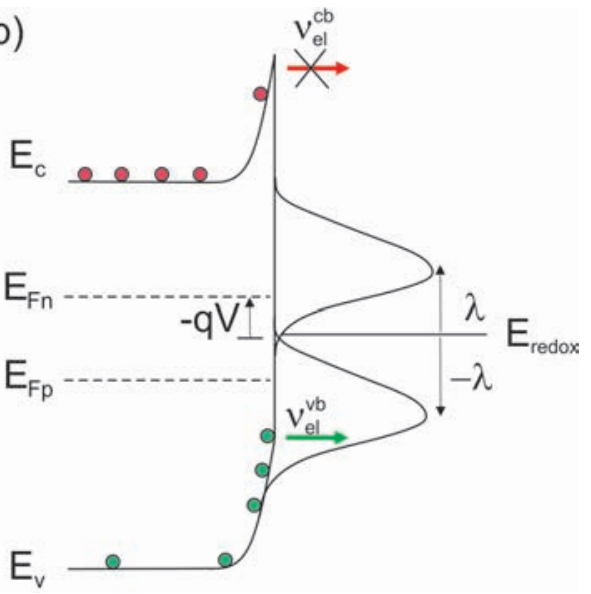

Figure 1.4: Energy diagrams corresponding to a photoanode, where (a) electronic charge transfer is limited by lowering down the position of the redox energy level, $E_{\text {redox }}$, with respect to the conduction band, (b) electron transfer is inhibited and hole transfer enhanced by using a semiconductor whose band positions properly match the redox level, $E_{\text {redox }}$, and by creating a Schottky barrier, which allows removing electrons from the semiconductor/electrolyte interface and accumulating holes at this interface

For the examples we are discussing here, electron transfer must be avoided while hole transfer must be enhanced. Therefore, the conduction band must be as far as possible from the center of the Gaussian centered in $E_{\text {redox }}+\lambda$, while the valence band must be as close as possible from the center of the Gaussian centered in $E_{\text {redox }}-\lambda$. This configuration can be achieved by changing the value of the reorganization energy and/or the redox level by choosing the redox couple with the right energy level and/or by varying the relative concentration of the oxidant and reductant, as shown in Figure 1.4. An alternative possibility to inhibit electron transfer is to reduce the value of the parameter $A_{e l}^{c b}$ in Equation 1.4a, while hole transfer can be enhanced by increasing $A_{e l}^{v b}$ (Equation 1.4b). To fulfill such purpose, one can use coating layers, which directly decrease the kinetics of electron charge transfer, and adequate catalysts which improve the oxidation reaction. ${ }^{25,26}$

\subsubsection{Tuning carrier densities}

Equation 1.2 suggests that the second parameter which can be tuned in order to optimize the kinetics of charge transfer is the carrier density at the semiconductor/electrolyte interface. For the case of photoanodes used for solar fuel production, it is necessary to reduce the density of electrons, $n$. 
Within the Boltzmann approximation:

$$
n=N_{c} \exp \left(-\frac{q V}{k_{B} T}\right) \exp \left(\frac{E_{F 0}-E_{c}}{k_{B} T}\right)
$$

Where $N_{c}$ is the electron density at the bottom of the conduction band edge. At equilibrium, $V=0$. In order to minimize $n$, a Schottky barrier can be formed at the semiconductor/electrolyte interface with the use of a doped semiconductor (Figure 1.4p). The electric field at the Schottky barrier allows removing electrons from the semiconductor/electrolyte interface and provides a driving force for holes to reach such interface. ${ }^{27}$ However in the case of nanostructured semiconductors, the surrounding electrolyte, whose dielectric constant is high, may shield the electric field, as first demonstrated for the case of DSCs, ${ }^{28}$ and it is not possible to apply such method.

We shall now introduce the effect of the applied voltage and illumination on direct charge transfer processes. As previously mentioned, voltage and illumination only affect carrier densities in the semiconductor but not the kinetics of direct charge transfer. In the photoelectrochemical devices discussed so far, voltage controls the density of majority carriers. For photoanodes used for solar fuels production, the density of electrons is directly modulated by the applied bias. ${ }^{29}$ In fact, when cathodic voltage is applied $(V<0)$ the density of electrons at the semiconductor/electrolyte interface increases along with electron charge transfer. The reverse situation is obtained at anodic bias. In addition under illumination, holes are photogenerated, which activates the oxidation reaction. In this case the hole Fermi level, $E_{F p}$, is split from the electron Fermi level, $E_{F n}$. If hole transfer is infinitely fast, $E_{F p}$ equilibrates with the redox level $\left(E_{F p}=E_{r e d o x}\right)$. Otherwise, if hole transfer is sluggish, such equilibration cannot be achieved and $E_{F p}<E_{\text {redox }}$, as shown in Figure 1.4b.

\subsubsection{Influence of surface states}

Charge transfer processes depicted in Figure 1.4 correspond to an ideal situation where free carriers at the semiconductor/electrolyte interface are directly transferred from the conduction or valence band to the electrolyte. Nonetheless, a substantial density of surface states may be present at such interface.

Two types of states can be distinguished: intrinsic and extrinsic surface states. Intrinsic surface states are due to the semiconductor itself. In fact, when the periodicity of the crystal structure is locally broken, apparition 
of defects within the band gap may occur. In particular, the heteronuclear splitting of bonding interactions give rise to ionic surface states which are named Tamm states; ${ }^{30}$ while homonuclear splitting of covalent bonds is responsible for the creation of unsaturated radical states, dangling bonds, called Shockley states. ${ }^{31}$ Tamm states are energetically close to the semiconductor bands: cationic Tamm states are close to the conduction band while anionic ones are formed in the vicinity of the valence band. These types of defects are present in commonly used oxides such as $\mathrm{TiO}_{2}$ and $\mathrm{ZnO}$ but also in large band gap chalcogenides such as CdS and ZnS. On the contrary, Shockley states are deep in the semiconductor band gap and are very reactive. The distribution of such surface states may be strongly influenced by the contacting electrolyte at the semiconductor/electrolyte interface. In practice, it is therefore impossible to a priori predict with accuracy the distribution of these states.

Extrinsic surface states are created by the interaction between the semiconductor and an extrinsic source. In the case of the semiconductor/ electrolyte, species from the electrolyte may adsorb at the semiconductor surface and create new electronic states. ${ }^{32}$ These states may result from the interaction of the highly reactive Shockley intrinsic states and the adsorbate species from the electrolyte. The relative distribution of extrinsic and intrinsic surface states is therefore dictated by the nature of the electrolyte and the interaction between both kinds of states. In addition, under non equilibrium conditions, when applying voltage or illuminating the semiconductor, new transitory species involved in multiple step redox reactions may be created. These species can be temporarily adsorbed at the semiconductor surface and behave as transient surface states, as in the case of $\mathrm{TiO}_{2} \cdot{ }^{33}$ Just like static states, transient surface states can also influence the steady state characteristic of solar devices. However they remain difficult to detect.

The distribution of surface states is usually assumed to follow three types of patterns, which are depicted in 1.5 . The simplest case is the one shown in Figure $1.5 \mathrm{a}$, which corresponds to a mono-energetic density of surface states, $N_{s s}$ (sometimes noted $N_{t}$ ), distributed at a given energy level $E_{s s}$. However, one expects fluctuations in the energy distributions of such states around the energy $E_{s s}$, and a Gaussian model is usually more appropriate, as shown in Figure $1.5 \mathrm{~b}$. In this case the total density is usually noted $N_{L}$, in reference to the density of localized states, and the energy fluctuations of the density of surface states is given by the variance $\sigma_{l}$. Such distribution is a feature of Tamm states in organic semiconductors, which populate the highest occupied molecular orbital (HOMO) and lowest unoccupied molecular orbital (LUMO). ${ }^{34}$ On the contrary, inorganic semiconductors usually present an exponential distribution of Tamm states, shown in Figure 1.5c, 
which is related to the Urbach tail in optical absorption measurements. ${ }^{35}$ This type of DOS not only depends on the total density of localized states $N_{L}$ but also on the parameter $\alpha$, which reflects the penetration depth of the exponential DOS in the semiconductor band gap. $\alpha$ is sometimes written as a function of the parameters $T_{0}$, which has temperature units: $\alpha=T / T_{0}$.

(a)

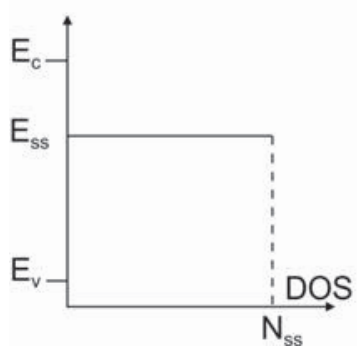

(b)

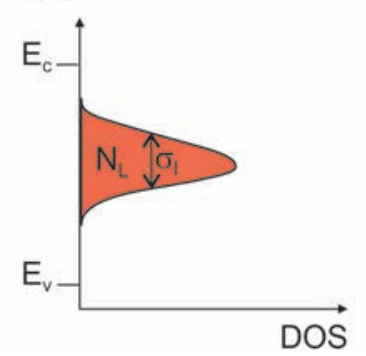

(c)

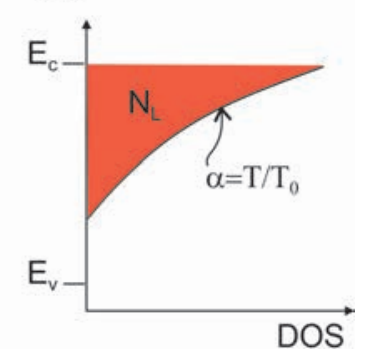

Figure 1.5: Three commonly used models for the description of the energy distribution of the density of surface states in semiconductors: (a) mono-energetic density of states, $N_{s s}$, at the energy level $E_{s s}$, (b) Gaussian density of states with standard deviation $\sigma_{l}$, (c) exponential distribution characterized by the factor $\alpha$, which regulates the depth of the distribution of states within the band gap: the smaller $\alpha$, the deeper the distribution. $\alpha$ is sometimes expressed as a function of the temperature, $T$, and a parameter with temperature units $T_{0}$. The total density of surface states in (b) and (c) is $N_{L}$.

The DOS can be measured by physical methods such as ultra-high vacuum techniques (UHV) like XPS, UPS etc. ${ }^{36}$ However these techniques are performed ex situ and one cannot extract the electronic properties of the semiconductor/electrolyte interface in real conditions. Since the distribution of surface states is strongly dependent on the nature of the semiconductor/electrolyte interface, it is therefore crucial to perform measurements in situ. Several optical and X-ray spectroscopy techniques allow recovering the DOS of surface states in situ. ${ }^{37}$ Nevertheless, these techniques are restricted to a few specific cases. To such extent, it is useful to resort to electrochemical techniques, which will be introduced in Chapter 2

Surface defects may provide other pathways for recombination and/or charge transfer. In fact, inner band gap states may affect direct charge transfer in two ways, as depicted in Figure 1.6. The first situation, shown in Figure 1.6 $\mathrm{a}$, is the classical picture used to describe charge transfer at the $\mathrm{TiO}_{2} /$ electrolyte interface in DSCs and QDSCs. ${ }^{38}$ In this case, surface states act as intermediates for indirect charge transfer (green arrow), which is harmful for energy production. The second situation corresponds to direct charge transfer from the valence band in competition with indirect charge transfer in presence of surface states for solar fuel production. For this type 
(a)

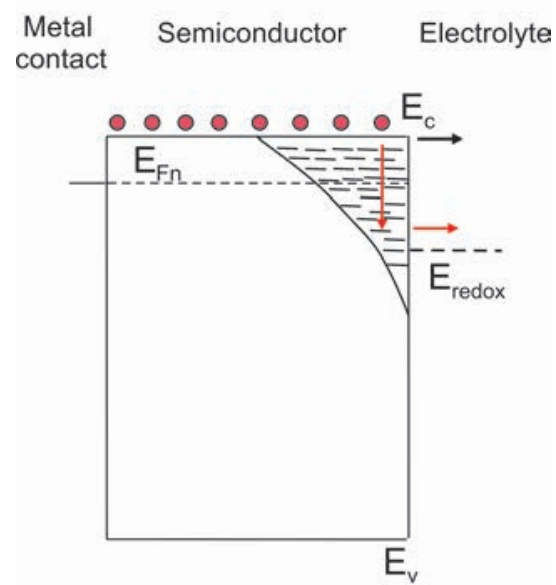

(b)

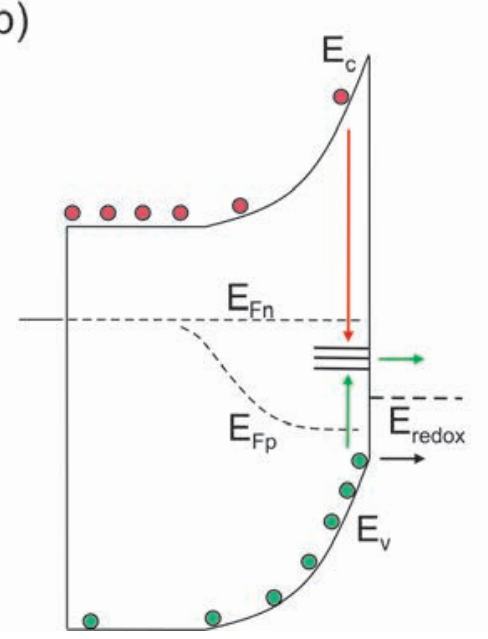

Figure 1.6: Charge transfer models used in the literature in the presence of surface states. (a) In this configuration, one single type of carrier is injected into the semiconductor and electron transfer from the conduction band (black arrow) and surface states (red arrows) are the only processes governing the overall charge transfer. This approach is commonly used for the description of the $\mathrm{TiO}_{2} /$ electrolyte interface in DSCs and QDSCs. (b) Case of a photoanode used for solar fuel production. In this approach direct charge transfer from the valence band (black arrow) is in competition not only with the indirect charge transfer from surface states (green arrows) but also with electron-hole recombination induced by electron capture in surface states (red arrow).

of applications, surface states may not only be a charge transfer intermediary but can also induce losses of electrons and holes which recombine when simultaneously captured in surface states. ${ }^{39}$ This is the so called Shockley- 
Read-Hall recombination. ${ }^{40}$ For energy storage purpose charge transfer from surface states may not necessarily be a drawback, as long as electron-hole recombination is minimized. However electron-hole recombination, direct and indirect charge transfer are usually coupled, and it is not clear whether these states are an asset for charge transfer. Hence it is crucial to decouple these processes.

In the last few years, lots of efforts have been made in order to avoid undesirable surface state assisted recombination effects by optimizing the deposition procedure or using surface treatments. The deposition procedure can be improved via the deposition technique itself. Many techniques have been used in the literature for the optimization of charge transfer at the semiconductor/electrolyte interface such as electro-deposition, atomic layer deposition (ALD), ultrasonic spray pyrolysis (USP), doctor blade, spin coating, atmospheric pressure chemical vapor deposition (APCVD) and so on. ${ }^{41}$ In addition, thermal treatment can also influence drastically the presence of surface states. For instance, Hamann and coworkers showed that surface states could be selectively removed by using ALD and annealing hematite at $800^{\circ} \mathrm{C} .{ }^{42}$ Note that in general material morphology is very sensitive to the nature of the material and environmental conditions, and engineering of the deposition procedure is a complex science.

Surface treatments have also been investigated, using catalysts and overlayers aiming at enhancing the kinetics of charge transfer processes for solar fuel production. ${ }^{43}$ However, it is not clear whether these methods enhance the kinetics of the direct or indirect charge transfer or passivate the inner band gap recombination centers. ${ }^{44}$ In fact, an efficient optimization of the charge transfer reaction requires the prior knowledge of the limiting processes. As previously mentioned, the approaches available in the literature do not allow one to getting sufficient insight for the proper choice of materials with the satisfactory functions. One of the goals of this Thesis is to develop advanced characterization relying on solid physico-chemical models of the semiconductor/electrolyte interface in order to recover in situ the density of surface states along with the kinetics of charge transfer.

\subsubsection{Influence of bulk recombination}

In addition to the surface effects previously described, it is important to introduce the effect of the spatial extension of the semiconductor on charge transfer. In fact, just like surface states, the bulk of the semiconductor may affect substantially the density of free carrier at the semiconductor/ electrolyte interface. 


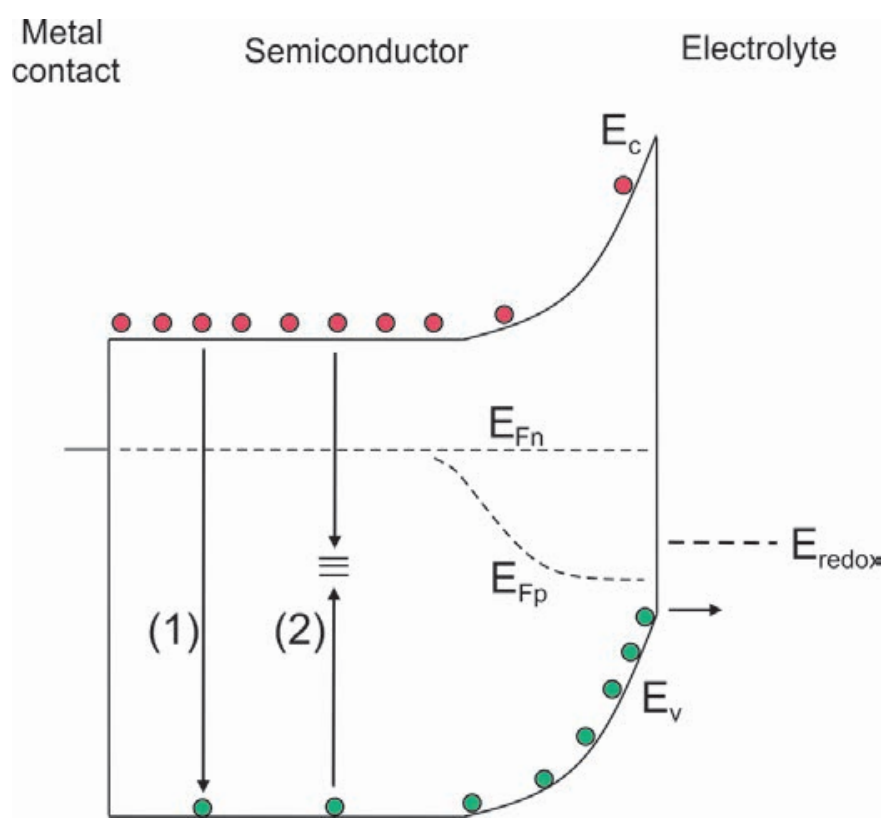

Figure 1.7: Main bulk recombination processes occurring in semiconductors used for photovoltaic applications: (1) band to band recombination of electrons from the conduction band and holes from the valence band, (2) Shockley-Read-Hall recombination induced by the simultaneous trapping of electrons and holes.

There are two main types of bulk recombination processes affecting carrier densities in semiconductors used for photovoltaic applications. These mechanisms are summarized in Figure 1.7. The first one (1), is a band to band recombination process. This process occurs when excitons, polarons or non interacting free electrons in the excited state recombine with holes in the ground state. The recombination rate for band to band recombination is described by the general equation $U_{r}=B\left(n p-n_{i}^{2}\right)$, where $B$ is a prefactor which depends on the electric field in the case of the non-geminate Langevin recombination. ${ }^{45}$ In the case of a doped semiconductor such that the concentration of majority carriers is not affected by the generation and recombination processes, recombination only depends on the minority carrier concentration. For instance, in the case of an n-type semiconductor, the recombination rate is simplified into $U_{r}=\left(p-p_{0}\right) / \tau$. This type of recombination is mostly radiative.

The second one (2), is the Shockley-Read-Hall recombination, which in this case occurs within bulk states, instead of the surface states mentioned in section 1.2.2 ${ }^{40}$ We shall emphasize here that $\mathrm{SRH}$ recombination is all the more probable as recombination centers are close to the middle of the 
band gap, when the electron and hole capture probabilities are similar. This type of photonic process becomes negligible as the energy level of the states is closer to the semiconductor bands. The expression of the Shockley-ReadHall recombination rate, $U_{r}$, will be discussed later on in this Thesis. Note that this type of recombination is usually faster than the band to band recombination and is mostly non-radiative.

Another recombination process, which is not represented in Figure 1.7 is Auger recombination. ${ }^{46}$ This process occurs at high carrier densities and is usually not significant for photovoltaic applications. In fact, this process involves three carriers. When an electron from the excited state relaxes to the ground state, the loss of energy can either be conserved by emission of a photon (band to band recombination) or be transmitted to another electron in the excited state (Auger recombination). In this case, the latter electron is promoted to higher energy levels within the same band of energy and can subsequently decay to lower energy states by thermalization.

It should be noted that all recombination processes may also be classified into two categories: geminate and non-geminate recombination. ${ }^{47}$ Geminate recombination occurs when geminate pairs, originating from the same absorption event, recombine. This is the case of excitonic recombination, which, for instance, may take place at the donor/acceptor interface in the blend of organic solar cells. The opposite process is the non-geminate recombination, which takes place between two carriers of opposite charges, generated by two distinct generation events, and which have undergone transport within the semiconductor before recombining.

In any case, these recombination processes represent a waste in terms of solar energy conversion and should be limited, even though radiative recombination cannot be eliminated. This can be achieved either indirectly by enhancing charge extraction at the selective contacts or by directly reducing bulk recombination. In general, apart from optimizing the deposition procedure (technique, temperature treatment etc), mentioned in section 1.2.2, two possible types of solutions can be adopted to limit bulk recombination. Indeed, nanostructuring the semiconductor and material combination have proven to be efficient methods.

Firstly, nanostructuring allows reducing the bulk of the semiconductor and has appeared as an efficient method to limit significantly bulk recombination. ${ }^{48}$ In addition, nanostructured materials offer larger active areas, which enhances charge transfer at the semiconductor/electrolyte interface. Several morphologies have been studied in the literature, which have allowed reducing significantly bulk recombination. In Figure 1.8, we present a few examples of morphologies for the case of hematite, titanium oxide and 
tungsten oxide. The cauliflower (Figure 1.8 a) ${ }^{49}$ nanotube (Figure 1.8b) ${ }^{50}$ and helicoidal (Figure 1.8 $\mathrm{d})^{51}$ morphologies have allowed enhancing substantially the efficiency of the solar to fuel conversion by hematite and tungsten oxide based photoanodes. However reducing the influence of the semiconductors bulk does not prevent surface recombination. In fact, nanostructured semiconductors present more grain boundaries and are prone to present a higher number of surface defects, as for the case of the submicron $\mathrm{TiO}_{2}$ particles presented in Figure 1.8c. ${ }^{52}$ Therefore a compromise must be reached in order to find a balance between reduction of bulk recombination and increase of surface losses.

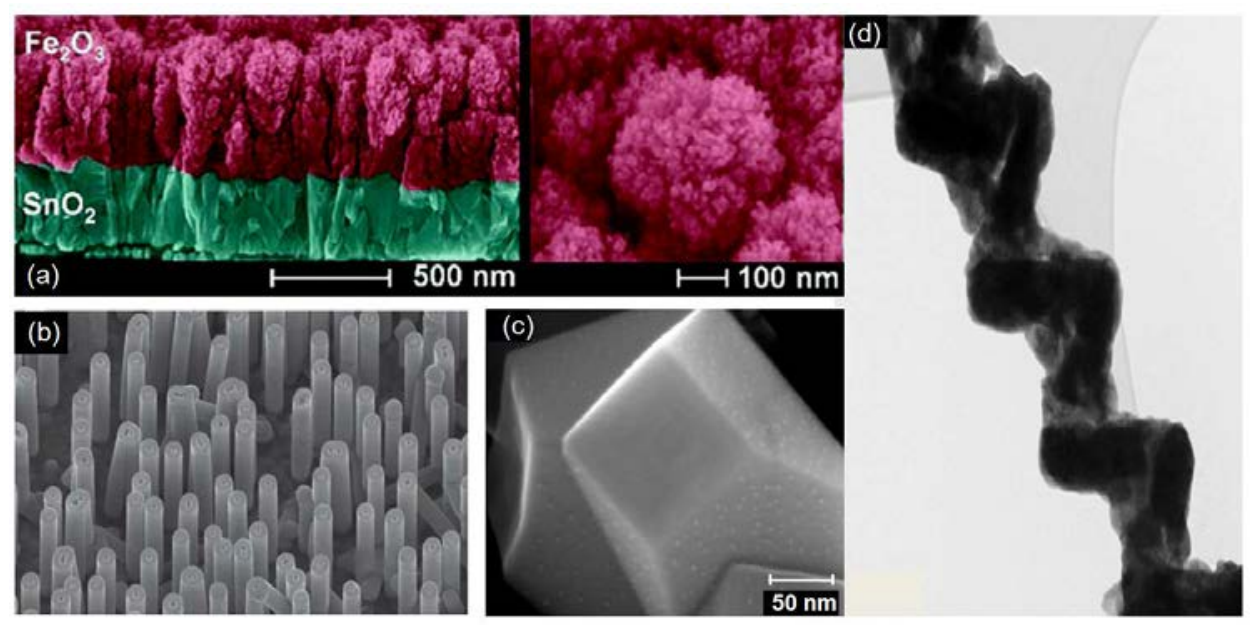

Figure 1.8: (a) Mesoporous silicon doped $\mathrm{Fe}_{2} \mathrm{O}_{3}$ on conducting glass (reproduced from ref. 49]) (b) Hematite-coated transparent conductive nanotubes coated with aluminum doped zinc oxide (AZO) (reproduced from ref. 50]) (c) Truncated octahedron $\mathrm{TiO}_{2}$ particles after chronoamperometry measurements after applying $20 \mathrm{~s}$ at $0 \mathrm{~V}$ (reproduced from ref. [52]) (d) TEM image of the helical $\mathrm{WO}_{3}$ (reproduced from ref. [51]).

Secondly, separation of the absorption and electronic transport properties by material combination may also be a relevant solution. However the semiconductor/electrolyte interface may also be strongly affected and it is convenient to combine such material processing with the use of surface catalysts. For example, material combination has proven to be successful for water splitting applications. In fact, tungsten oxide, $\mathrm{WO}_{3}$, and bismuth vanadate, $\mathrm{BiVO}_{4}$, give poor photoelectrochemical performances. When combining both materials, higher photoanodic currents can be obtained. ${ }^{53}$ However the onset voltage that must be applied for the oxidation reaction to take place remains high. In this case, the concomitant use of a surface catalyst strongly improves charge transfer at the semiconduc- 
tor/electrolyte interface. ${ }^{54}$ However it is not always clear whether material combination directly reduces bulk recombination or enhances the kinetic of direct charge transfer. In addition, the role of the surface catalyst is not obvious: both direct and indirect charge transfer could a priori be enhanced.

Finally, it must be remarked that in general it is not always clear whether the three techniques previously mentioned allow reducing bulk recombination by enhancing charge extraction at the contact or by directly reducing the rate of bulk recombination. Furthermore, in some cases, reducing bulk recombination may increase surface recombination. It is therefore crucial to monitor charge storage modes and recombination processes during the optimization of photoelectrochemical devices.

\subsubsection{Optimization of charge transfer}

So far we have considered the separate influence of surface states and bulk recombination on charge transfer at the semiconductor/electrolyte interface. However in practice, these features are combined. Hence, the optimization of charge transfer processes requires previous in situ identification of the prevailing limiting mechanism. The first step consists in identifying the bulk or surface nature of the limiting process. If bulk recombination is the prevailing limiting process, several solutions can be contemplated, as mentioned in section 1.2.3. However optimization of the bulk recombination may induce higher surface state density when changing the deposition method, nanostructuring the electrode or combining materials. It is therefore crucial to monitor surface recombination and check how bulk treatments concomitantly influence charge transfer processes at the interface.

If charge transfer processes turns out to be limiting photoelectrochemical performances, it is necessary to discriminate between direct charge transfer from the conduction/valence band and indirect charge transfer from surface states. If direct charge transfer is the limiting process, the solution proposed in section 1.2.1. can be adopted. If indirect charge transfer from surface states is the limiting process, further characterization must be performed in order to identify if slow charge transfer or high recombination kinetics is harmful for charge transfer at the semiconductor/electrolyte interface. Such discrimination allows one resorting to the adequate solutions, as mentioned in 1.2 .2 ,

The analysis of these mechanisms can be performed in-situ by electrochemical and photoelectrochemical techniques. However, it is a priori impossible to decouple all the faradic processes (recombination/charge transfer) from a single steady state measurement such as a current-voltage $(j V)$ 
characteristic. In fact, in such measurements, the current is measured after applying a given potential for a time sufficient to observe current stabilization. In other words, a $j V$ curve does not allow one to probing the various faradic contributions that induce current variations when applying potential. In this case, current variations can be accounted for by a single parameter, usually named the dc or total resistance, which embraces all the contributions to current variations:

$$
R_{d c}=\left(\frac{\partial j}{\partial V}\right)^{-1}
$$

Resorting to the dc resistance allows eliminating unnecessary information present in a $j V$ curve, which blurs the analysis of the recombination processes. In fact the dc resistance permits to have a clear and general picture of the voltage dependent processes, (i.e. recombination), by eliminating the contributions from constant sources, which do not vary with voltage, (carrier photogeneration). Therefore, it is a very convenient way to compare recombination processes for different devices

In the framework of the classical diode model, current increases exponentially with voltage, and so does the dc resistance. The competition between various faradic processes is at the origin of the non-ideal diode behavior, generally modeled by an ideality factor, $m$, and for a given electrode, $R_{d c}$ is usually written as $R_{d c}=R_{0} \exp \left( \pm q V /\left(m k_{B} T\right)\right)$, the sign + or - being dependent on the anodic or cathodic nature of the current.

Steady state resistance measurements are valuable tools for comparison. In fact in order to assess the relative importance of bulk and surface recombination, one can analyze steady state performance of devices with different thicknesses, which allow distinguishing between interfacial and bulk processes. In addition, one can also study devices with different architectures, contacts or absorber materials and compare the difference in total resistance in order to provide a qualitative assessment of the relative importance of interfacial and bulk processes. In order to illustrate this latter concept, it is useful to resort to the simple Reichman model of the semiconductor/electrolyte interface. ${ }^{55}$ This model uses the standard assumption that the voltage $V$ applied to the semiconductor electrode modifies the size of space charge region and introduces a kinetic limitation to the extraction of minority carriers to the fuel production reaction. The hole extraction current density is given by the expression

$$
j=q S_{p}\left(p_{s}-p_{s 0}\right)
$$

Here $p_{s}$ is the concentration of holes at the surface, and the parameter $S_{p}$ is 
similar to a hole surface recombination velocity. The current is found by a combination of unity collection efficiency in the space charge region (SCR), and by the solution of diffusion-recombination equation in the neutral region. Neglecting recombination in the SCR, the current as a function of voltage has the form

$$
j=\frac{j_{p h}-j_{0} \exp \left(-\frac{q V}{k_{B} T}\right)}{1+\frac{j_{0}}{j_{s 0}} \exp \left(-\frac{q V}{k_{B} T}\right)}
$$

Here $j_{p h}$ is the photocurrent given by Gartner's model, ${ }^{56} j_{0}$ is the reverse saturation current, and $j_{s 0}=-q S_{p} p_{s 0}$ is the charge transfer current at equilibrium. The resistance is given by the expression

$$
R_{d c}^{-1}=\frac{q j_{0}}{k_{B} T}\left(1+\frac{j_{p h}}{j_{s 0}}\right) \frac{\exp \left(-\frac{q V}{k_{B} T}\right)}{\left(1+\frac{j_{0}}{j_{s 0}} \exp \left(-\frac{q V}{k_{B} T}\right)\right)^{2}}
$$

In Figure 1.9 a we show the corresponding $j V$ curves for different values of the extraction parameter $S_{p}$. First we note that if the extraction velocity is infinite, then the $j V$ curve is similar to a diode curve

$$
j=j_{p h}-j_{0} \exp \left(-\frac{q V}{k_{B} T}\right)
$$

This behavior corresponds to the black solid line in Figure 1.9 a. In this idealized model the total resistance is an exponential function with no minimum feature, as shown in Figure $1.9 \mathrm{~b}$. When the transfer of holes has some limitation, recombination in the neutral region is favored near the flatband potential, and the photovoltage is displaced to lower values. In this case a minimum of the resistance is observed. Consequently the presence of a minimum in the total resistance indicates sluggish carrier extraction.

Yet, steady state resistance measurements are generally limited to a qualitative analysis. To such extent, time/frequency dependent techniques allow a more quantitative approach to decouple the different faradic mechanisms governing current-voltage characteristics of an electrode. In fact, each process $i$ occurs within a characteristic time $\tau_{i}$. Depending on the characteristic time associated to each process, one technique may be more adequate than another. For instance, ultra fast transient absorption spectroscopy (TAS) is very useful to study the processes occurring during the first instants following photo-generation, for a time window ranging from femtoseconds to nanoseconds. ${ }^{57}$ Such processes may be associated to charge injection, exciton dissociation or recombination etc. For slower processes 

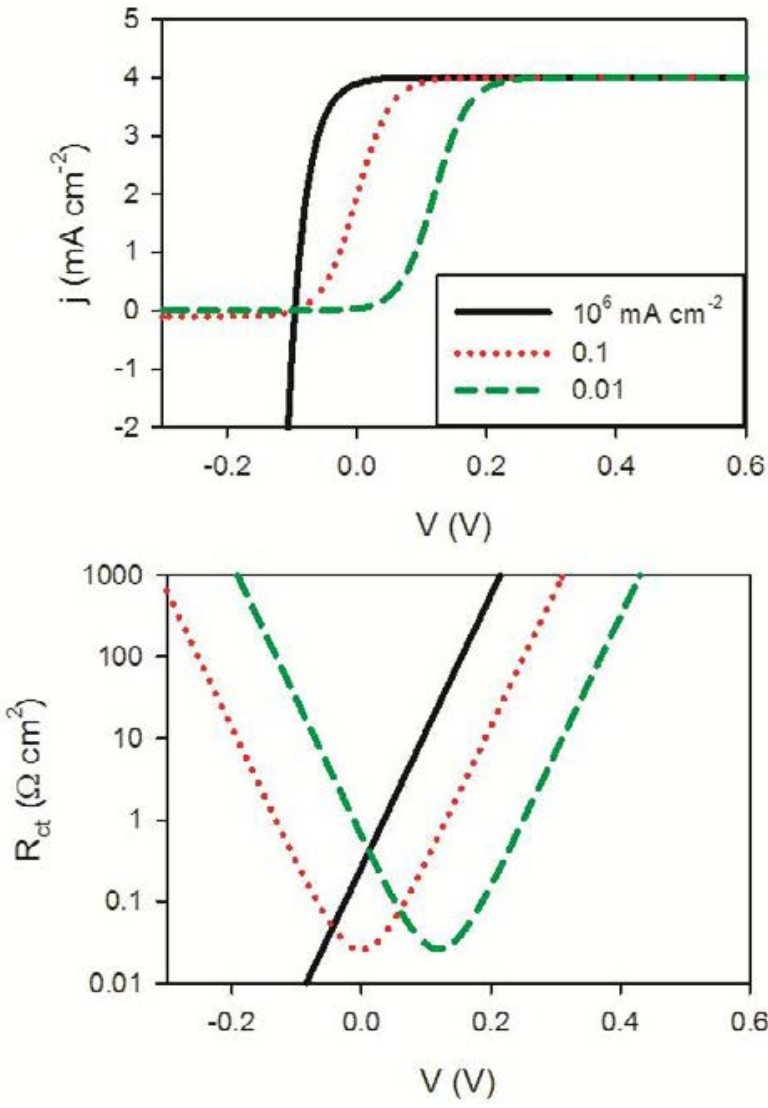

Figure 1.9: Current voltage curve of a photoanode (a) and charge transfer resistance (b) in the model of Reichman with extraction limitation for the minority carrier at the semiconductor/electrolyte interface. The photocurrent is $j_{p h}=4$ $\mathrm{mA} \mathrm{cm}{ }^{-2}$, the reverse saturation current is $j_{0}=0.1 \mathrm{~mA} \mathrm{~cm}^{-2}$, and the hole charge transfer current $j_{s 0}$ is indicated in the inset panel.

such as electronic transport, band to band and Shockley Read Hall recombination or charge transfer at the semiconductor/electrolyte interface, other techniques probing time scales ranging from microseconds to seconds are necessary. Such methods allow decoupling faradic processes by activating capacitive processes via a frequency/time dependent perturbation of voltage or current. In fact, for linear processes, each characteristic time $\tau_{i}$ can be related to a resistance value $R_{i}$ and a capacitance value $C_{i}$ as $\tau_{i}=R_{i} C_{i}$. ${ }^{58}$

In electrochemical measurements, voltage is regulated by splitting of the electrochemical levels from their equilibrium position, i.e. by the Fermi 
levels associated to electrons and holes. The splitting of the electrochemical energy levels is related to a variation of the total charge, $Q$, either by carrier density variations, governed by the classical continuity equations or by electrical field variations, governed by Poisson equation. It is therefore possible to distinguish between two main capacitive features. The first one, associated to carrier density fluctuations when changing the electrochemical potential, $\nu_{k}=-E_{F k} / q(\mathrm{k}=\mathrm{n}, \mathrm{p})$, is called the chemical capacitance. ${ }^{59}$ It reflects the charge variations in a given storage mode (conduction band, valence band, surface states) and is defined as:

$$
C_{\mu}=\frac{\partial Q}{\partial \nu_{k}}
$$

For photoelectrochemical devices, the voltage dependence of this capacitance at the semiconductor/electrolyte interface is well established in dark conditions, i.e. for the majority carrier only. In such condition, the chemical capacitance of the majority carrier is directly proportional to the density of free carriers and depends exponentially on voltage. ${ }^{60}$

(a)
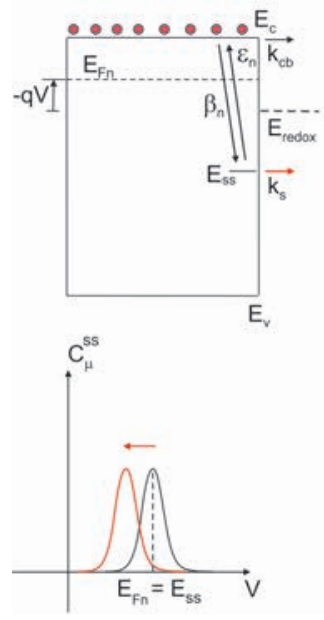

(b)
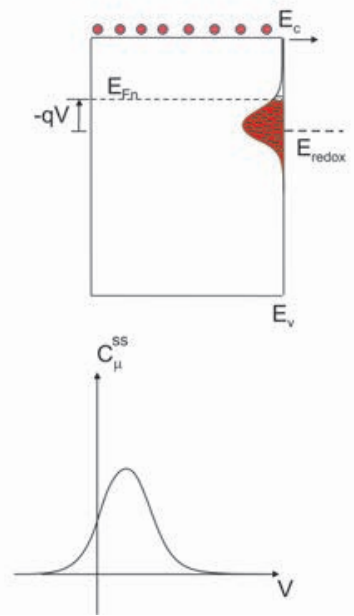

(c)
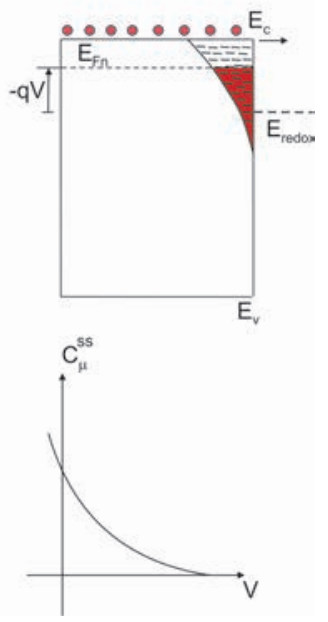

Figure 1.10: Energy diagram and corresponding surface state chemical capacitance commonly found in the literature for the case of an n-type material in dark conditions for (a) a density of mono-energetic surface states at the energy $E_{s s}$, with and without charge transfer from the surface states, (b) a Gaussian density and (c) an exponential distribution. Note that, in (b) and (c), the surface states occupation probability is treated within the zero temperature approximation. In Figure 1.10 , $k_{c b}$ is the rate constant for the reduction of cations in the electrolyte, while $k_{s}$ is the one for the reduction of the electrolyte by trapped electrons. In addition, $\beta_{n}$ is the trapping rate of electrons from the conduction band to the surface states and $\epsilon_{n}$ the detrapping rate. 
1.2. Charge transfer at the semiconductor/ electrolyte interface

In presence of surface states, the chemical capacitance associated to such states has been fully derived in the framework of the small perturbation approximation, i.e. when the chemical capacitance only depends on steady state quantities. ${ }^{61}$ For the case of a mono-energetic density of states (see Figure $1.5 \mathrm{a}$ ), the chemical capacitance displays a peak behavior with voltage, as shown in Figure 1.10 a. In absence of charge transfer, this peak occurs when surface states are half filled with electrons, i.e. when the Fermi level reaches the mono-energetic level $E_{s s}$. In presence of charge transfer from these states, the peak is displaced cathodically for an n-type semiconductor, since more electrons must be captured for surface states to be half filled with electrons. For the Gaussian and exponential distributions shown in Figure $1.5 \mathrm{~b}$ and $\mathrm{c}$, the surface state chemical capacitance has been derived with an additional assumption: the zero temperature approximation for the occupation probability of surface states. Under such hypothesis, surface states below the Fermi level are occupied with a probability 1 and above the Fermi level, the occupation probability is 0. In this case, the chemical capacitance is proportional to the density of surface states, as shown in Figure $1.10 \mathrm{~b}$ and c. However, to the best of our knowledge, the chemical capacitance of surface states and the one associated to the storage mode of the minority carrier (conduction or valence band) has not been derived for large perturbation techniques and under illumination.

The second capacitive feature, $C_{F}$, is associated to the variations of the electrical field, $F$, and is detected through the displacement current:

$$
C_{F}=\frac{\epsilon_{0} \epsilon_{r} A}{w}
$$

Where $\epsilon_{0}$ is the vacuum dielectric permittivity, $\epsilon_{r}$ the relative permittivity, $A$ is the area of the semiconductor and $w$ is the depletion region width. At the semiconductor/electrolyte interface, we may distinguish between two types of electrostatic capacitances, as shown in Figure 1.11. The first one arises from the variation of the total number of ionized dopants with voltage, which induces fluctuations of the depletion region width, $w$, with voltage. This capacitance is called the semiconductor capacitance, $C_{s c}$, and is shown in Figure 1.11. In this case, $w(V)=\left[2 \epsilon_{0} \epsilon_{r}\left(V_{b i} \pm V\right) /\left(q N_{\text {dopant }}\right)\right]^{1 / 2}, V_{b i}$ being the built-in potential and $N_{\text {dopant }}$ is the density of dopants. ${ }^{62}$ The sign + corresponds to an n-type material while the sign - corresponds to a p type material. It is usually more convenient to analyze such capacitance in the Mott Schottky plot where $C_{s c}^{-2}$ is represented as a function of the applied voltage, as shown in Figure 1.11k. In this representation, a linear trend is obtained until the depletion region width reaches the length of the device, $L,(w=L)$. In this case, $C_{s c}$ reaches its minimum value, $C_{s c}=\epsilon_{0} \epsilon_{r} A / L$, which is typically of the order of $10^{-7}-10^{-8} \mathrm{~F} / \mathrm{cm}^{2}$. 
(a)

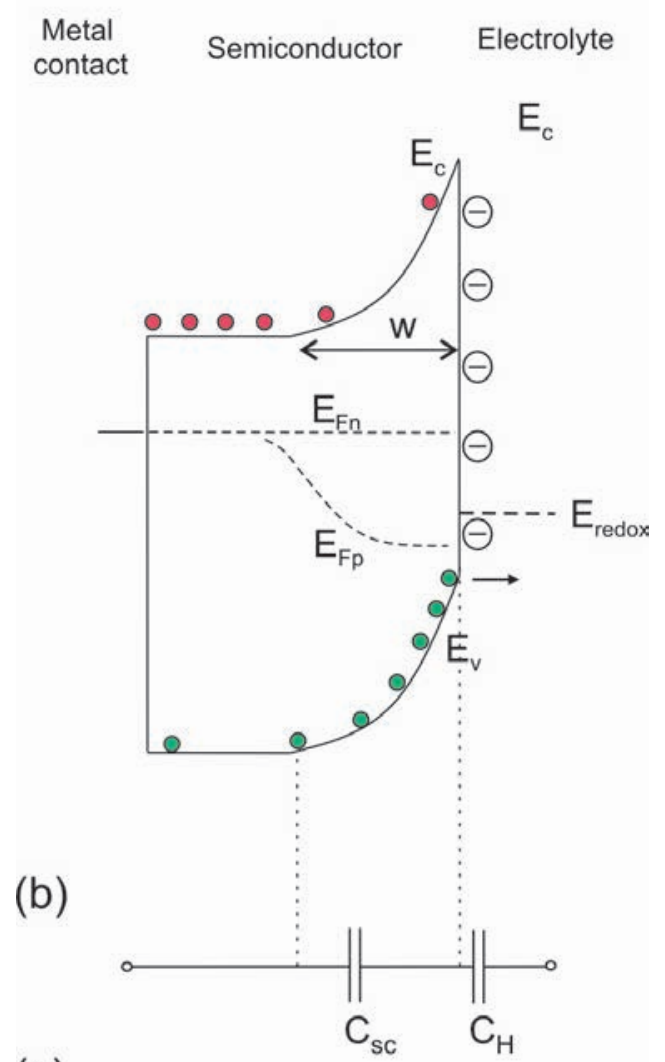

(c)

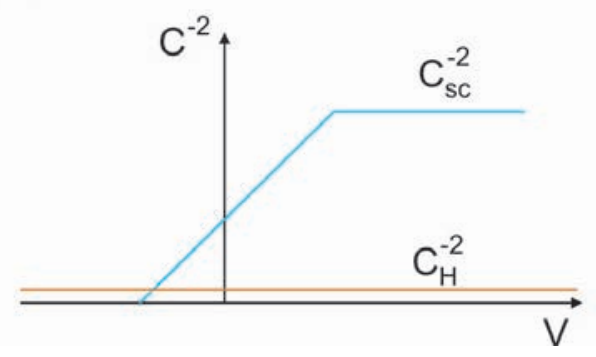

Figure 1.11: (a) Energy diagram of the semiconductor/electrolyte interface for a photoanode featured by a depletion region of width $w$. In this region the net charge is positive and is compensated by anions from the electrolyte, which accumulate at the surface of the semiconductor, forming a double layer called the Helmholtz layer. (b) The depletion region can be modeled by a capacitance, namely the semiconductor capacitance, $C_{s c}$, in series with the Helmholtz capacitance, $C_{H}$, associated to the double layer. (c) General trend of the corresponding Mott-Schottky plot for both capacitances. 
1.2. Charge transfer at the semiconductor/ electrolyte interface

The second type of electrostatic capacitance arises from the compensation of the net charge at the semiconductor surface by counter ions from the electrolyte. Such ions accumulate at the semiconductor surface and create a double layer. ${ }^{63}$ If the concentration of ions in the electrolyte is large enough, this double layer can be considered as a plane capacitor called the Helmholtz layer. On the contrary, if the concentration of ions is low, phenomenon of ion diffusion will be significant and the capacitance of the double layer depends on the applied voltage. In this latter case, the diffuse double layer is called the Gouy-Chapman layer. Here we neglect ion diffusion in the electrolyte and describe the capacitive contribution of the electrolyte via the Helmholtz capacitance, usually noted $C_{H}$. For the sake of simplicity, $C_{H}$ and $C_{s c}$ can be viewed as two capacitors in series since charge conservation imposes that when the net charge in the depletion region decreases, the number of counter ions in the electrolyte must decrease concomitantly and voltage at both capacitors varies. In addition, $C_{H}$ can be derived within the approximation of the capacitor plate, where the electrical field varies linearly with the applied potential between two plates separated by a distance $d$. Its expression is identical to the one of a fully depleted semiconductor $(w=d)$ and is $C_{H}=\epsilon_{0} \epsilon_{r} A / d$. The value of $C_{H}$ is usually of the order of $10^{-4}-10^{-5} \mathrm{~F} / \mathrm{cm}^{2}$.

Finally, it should be noted that $\epsilon_{r}$ may also depend on voltage and a more general expression of $C_{F}$ should be written in such condition. This is the case of dielectric relaxation for instance, which we have recently discussed for other types of solar cells. ${ }^{64}$ However, for the materials used in this Thesis, such effect has not been detected and will not be further discussed.

In summary, capacitance measurements allow one decoupling the faradic processes regulating charge transfer at the semiconductor/electrolyte interface. But it is also a powerful tool for identification of the carrier storage modes via the chemical capacitance, $C_{\mu}$, and detection of the presence of an electric field, which could regulate charge separation at this interface via the electrostatic capacitance, $C_{F}$. Capacitance measurements can be performed through small or large perturbation techniques in the time or frequency domain. In this Thesis we have used two popular methods: impedance spectroscopy (IS) and cyclic voltammetry (CV), detailed in sections 2.3 and 2.4 of the following chapter. 


\subsection{Outline and scope}

\subsubsection{Formulation of the problem}

Optimization of charge transfer at the semiconductor/electrolyte interface relies on clear identification and discrimination of the processes which control photoelectrochemical performances. Of particular importance are the material defects, which act as localized states in the band gap of the semiconductors used for photoelectrochemical applications. In fact, those states strongly affect bulk and/or surface recombination and charge transfer processes at the semiconductor/electrolyte interface. In the case of dye and quantum dot sensitized solar cells, where electronic transport involves one single carrier, solid electrochemical characterization tools have been developed over the past 20 years. Yet, for photoelectrochemical applications such as solar fuel production, both electrons and holes intervene in electronic transport and the current methods do not allow deconvoluting the processes associated to each carrier. Such limitation constitutes one of the bottlenecks for the optimization of solar devices used for solar fuel production. In particular, direct charge transfer from the conduction/valence, indirect charge transfer from surface states and trap mediated recombination should clearly be discriminated, and if possible in situ, under working conditions.

\subsubsection{Objectives}

The main objective of this Thesis is to understand the interaction between material defects and the processes which govern photocurrent in photoelectrochemical devices. The work performed during this $\mathrm{PhD}$ is intended to bridge the gap between characterization of the semiconductor/electrolyte interface and device optimization, by proposing a solid method based on chemical capacitance measurements, capable of distinguishing the main processes which control device operation in presence of both, electrons and holes. To reach this goal several objectives have been targeted:

- Study of the origin of the photocurrent in devices used for solar fuel production.

- Study of the role of surface states on the photocurrent production.

- Study of the nature of the surface states which affect the semiconductor/electrolyte interface.

- Study of the effect of the semiconductor morphology on photoelectrochemical performance. 


\subsubsection{Structure of the Thesis}

The investigation of the role of bulk and surface states on charge transfer at the semiconductor/electrolyte interface is presented throughout the body of this Thesis. Chapter 2 outlines the modeling methods and characterization techniques used in this Thesis. Chapter 3 establishes a theoretical framework for the study of the semiconductor/electrolyte interface. Chapters 4,5 and 6 explore the role of surface states on charge transfer at the semiconductor/electrolyte interface, while Chapter 7 elucidates the role of bulk trap states on bulk recombination and the corresponding IS response. Chapter 8 aims at solving the main problem addressed in this Thesis, based on the previous papers, and discusses the role of surface state and bulk recombination on charge transfer at the semiconductor/electrolyte interface. Chapter 9 consists of a general discussion of all the results obtained in this Thesis. The last chapter, Chapter 10, summarizes the main conclusions and suggests new outlooks. This Thesis is based on six papers, which have been published in international reviews and aim at addressing the issues and objective previously mentioned. Here we summarize the main results presented in each publication.

1. Chapter 3: Energy Diagram of Semiconductor/Electrolyte Junctions.

In this commentary, we have provided a consistent set of definitions and a diagram that allow one combining physical and photoelectrochemical conventions for the description of the semiconductor/ electrolyte interface.

2. Chapter 4: Equivalent Circuit of Electrons and Holes in Thin Semiconductor Films for Photoelectrochemical Water Splitting Applications.

A simple model for the kinetics of electrons and holes in a thin semiconductor film in photoelectrochemical water splitting conditions is discussed, with a focus to discriminate between trap-assisted recombination and charge-transfer processes. We formulate the kinetic model in terms of the measurements of impedance spectroscopy and discuss the application of the results for the interpretation of the current potential curve under photogeneration. We provide a rigorous structure of the fundamental equivalent circuit for photoelectrochemical water splitting systems including a new predicted feature that is a chemical capacitance of the minority carriers that can give rise, in combination with other standard features, to a total of three arcs in the complex plane. 
3. Chapter 5: Interpretation of Cyclic Voltammetry Measurements of Thin Semiconductor Films for Solar Fuel Applications.

A simple model is proposed that allows interpretation of the cyclic voltammetry diagrams obtained experimentally for photoactive semiconductors with surface states or catalysts used for fuel production from sunlight. When the system is limited by charge transfer from the traps/catalyst layer and by detrapping, it is shown that only one capacitive peak is observable and is not recoverable in the return voltage scan. If the system is limited only by charge transfer and not by detrapping, two symmetric capacitive peaks can be observed in the cathodic and anodic directions. The model appears as a useful tool for the swift analysis of the electronic processes that limit fuel production.

4. Chapter 6: Relaxation of Electron Carriers in the Density of States of Nanocrystalline $\mathrm{TiO}_{2}$.

Band gap localized states and surface states play a dominant role in the application of nanocrystalline metal oxides to photovoltaics and solar fuel production. Electrons injected in nanocrystalline $\mathrm{TiO}_{2}$ by voltage or photogeneration are mainly located in band gap states. Therefore, charging a nanoparticulate semiconductor network allows one to recover the density of states (DOS) in the energy axis. However, shallow traps remain in equilibrium with the conduction band electrons, while deep traps do not. We show that the characteristic peak of the apparent DOS mixes an exponential DOS and a monoenergetic surface state. A model that incorporates the traps kinetics proves to be very efficient to assess the important parameters that determine both contributions via variation of charging rate. Contrary to the common theory, we demonstrate that the peculiar capacitance peak of nanocrystalline $\mathrm{TiO}_{2}$ can be mainly attributed, in some cases, to deep traps in the exponential distribution.

5. Chapter 7: Theory of Impedance Spectroscopy of Ambipolar Solar Cells with Trap-Mediated Recombination.

The analysis of recombination in solar cells suggests in many cases the presence of trap-mediated recombination in the absorber. We present a theory of the recombination of electrons and holes, the ShockleyRead-Hall model, using the impedance spectroscopy technique. We derive the impedance functions and the corresponding equivalent circuit model. After examining some cases of interest, we show that two semicircles can be obtained in the recombination circuit only if 
the chemical capacitance associated with traps is substantially larger than the chemical capacitances of free electrons and holes in the absorber bands, while in the other cases the normal behavior of one recombination arc will be obtained.

6. Chapter 8: Charge Transfer Processes at the Semiconductor/ Electrolyte Interface for Solar Fuel Production: Insight from Impedance Spectroscopy.

Knowledge of the nature of charge transfer processes at the semiconductor/electrolyte interface is crucial for the optimization of semiconductors used for solar fuel production. In the literature, there are two types of charge transfer mechanisms: (i) direct hole transfer from the valence band and (ii) indirect hole transfer via surface states. In this paper, we discuss both processes in the steady state regime through full drift-diffusion simulations considering the concomitant influence of the electric field and surface states at the semiconductor/electrolyte interface. We discuss the role of surface states and valence band holes in the photoanodic current. We subsequently analyze both hole transfer processes in a dynamic regime via the impedance spectroscopy (IS) method. We provide a solid criterion to discriminate both mechanisms and discuss some experimental examples from the literature.

\subsection{References}

1 http://elpais.com/tag/cumbre_del_clima/a/

${ }^{2}$ Butler, M. A.; Ginley, D. S. Principles of Photoelectrochemical Solar Energy Conversion. Journal of Material Science 1980, 15, 1-19.

${ }^{3}$ O'Regan, B.; Gratzel, M. High-Efficiency Solar Cell Based on DyeSensitized Colloidal $\mathrm{TiO}_{2}$ Films. Nature 1991, 353, 737-740.

${ }^{4}$ Vogel, R.; Pohl, K.; Weller, H. Sensitization of Highly Porous, Polycrystalline $\mathrm{TiO}_{2}$ Electrodes by Quantum Sized CdS. Chemical Physics Letters 1990, 174, 241-246.

${ }^{5}$ Nozik, A. J. Quantum Dot Solar Cells. Physica E 2002, 14, 115-200.

${ }^{6}$ Mora-Sero, I.; Bisquert , J. Breakthroughs in the Development of Semiconductor-Sensitized Solar Cells. Journal of Physical Chemistry Letters 2010, 1, 0463052.

${ }^{7}$ Fujishima, A.; Honda, K. Electrochemical Photolysis of Water at a Semiconductor Electrode. Nature 1972, 238, 37-38. 
${ }^{8}$ Walter, M. G.; Warren, E. L.; McKone, J. R.; Boettcher, S. W.; Mi, Q.; Santori, E. A.; Lewis, N. S. Solar Water Splitting Cells. Chemical Reviews 2010, 110, 6446-6473.

${ }^{9}$ Smith, W. A.; Sharp, I. D.; Strandwitz, N. C.; Bisquert, J. Interfacial Band-Edge Energetics for Solar Fuels Production. Energy 83 Environmental Science 2015, 8, 2851-2862.

10 Tang, J.; Durrant, J. R.; Klug, D. R. Mechanism of Photocatalytic Water Splitting in $\mathrm{TiO}_{2}$. Reaction of Water with Photoholes, Importance of Charge Carrier Dynamics, and Evidence for Four-Hole Chemistry. Journal of the American Chemical Society 2008, 130, 13885-13891.

${ }^{11}$ Berger, T.; Monllor-Satoca, D.; Jankulovska, M.; Lana-Villarreal, T.; Gómez, R. The Electrochemistry of Nanostructured Titanium Dioxide Electrodes. ChemPhysChem 2012, 13, 2824-2875.

12 Zhang, Y.; Guo, Y.; Duan, H.; Li, H.; Sun, C.; Liu, H. Facile Synthesis of $\mathrm{V}^{4+}$ Self-Doped, [010] Oriented $\mathrm{BiVO}_{4}$ Nanorods with Highly Efficient Visible Light-Induced Photocatalytic Activity. Physical Chemistry Chemical Physics 2014, 16, 24519-24526.

${ }^{13}$ Santato, C.; Ulmann, M.; Augustynski, J. Photoelectrochemical Properties of Nanostructured Tungsten Trioxide Films. The Journal of Physical Chemistry B 2001, 105, 936-940.

${ }^{14}$ John, H. K.; Karl W. Frese, Jr. Photooxidation of Water at $\alpha-\mathrm{Fe}_{2} \mathrm{O}_{3}$ Electrodes. Journal of The Electrochemical Society 1978, 125, 709-714.

${ }^{15}$ Klahr, B.; Gimenez, S.; Fabregat-Santiago, F.; Hamann, T.; Bisquert, J. Water Oxidation at Hematite Photoelectrodes: The Role of Surface States. Journal of the American Chemical Society 2012, 134, 4294-4302.

${ }^{16}$ Dotan, H.; Mathews, N.; Hisatomi, T.; Gratzel, M.; Rothschild, A. On the Solar to Hydrogen Conversion Efficiency of Photoelectrodes for Water Splitting. The Journal of Physical Chemistry Letters 2014, 5, 3330-3334.

${ }^{17}$ Ager, J. W.; Shaner, M. R.; Walczak, K. A.; Sharp, I. D.; Ardo, S. Experimental Demonstrations of Spontaneous, Solar-Driven Photoelectrochemical Water Splitting. Energy \& Environmental Science 2015, 8, 2811-2824.

${ }^{18}$ Nielander, A. C.; Shaner, M. R.; Papadantonakis, K. M.; Francis, S. A.; Lewis, N. S. A Taxonomy for Solar Fuels Generators. Energy 83 Environmental Science 2015, 8, 16-25.

${ }^{19}$ Gratzel, M. Photoelectrochemical Cells. Nature 2001, 414, 338-344.

${ }^{20}$ Marcus, R. A. On the theory of oxidation-reduction reactions involving electron transfer. I. The Journal of Chemical Physics 1956, 24, 966. 
${ }^{21}$ Marcus, R. A. Exchange Reactions and Electron Transfer Reactions Including Isotopic Exchange. Theory of Oxidation-Reduction Reactions Involving Electron Transfer. Part 4. Faraday Discussion Chemical Society 1960, 29, 21.

${ }^{22}$ Marcus, R. A. On the Theory of Electron-Transfer Reactions. VI. Unified Treatment for Homogeneous and Electrode Reactions. The Journal of Chemical Physics 1965, 43, 679.

${ }^{23}$ Gosavi, S.; Marcus, R. A. Nonadiabatic Electron Transfer at Metal Surfaces. The Journal of Physical Chemistry B 2000, 204, 2067-2072.

${ }^{24}$ Bisquert, J.; Marcus, R. A. Device Modeling of Dye-Sensitized Solar Cells. Topics in Current Chemistry 2014, 352, 325-395.

${ }^{25}$ Maeda, K.; Domen, K. Photocatalytic Water Splitting: Recent Progress and Future Challenges. The Journal of Physical Chemistry Letters 2010, 1, 2655-2661.

${ }^{26}$ Reece, S. Y.; Hamel, J. A.; Sung, K.; Jarvi, T. D.; Esswein, A. J.; Pijpers, J. J. H.; Nocera, D. G. Wireless Solar Water Splitting Using Silicon-Based Semiconductors and Earth-Abundant Catalysts. Science 2011, 334, 645648

${ }^{27}$ Cendula, P.; Tilley, S. D.; Gimenez, S.; Bisquert, J.; Schmid, M.; Grätzel, M.; Schumacher, J. O. Calculation of the Energy Band Diagram of a Photoelectrochemical Water Splitting Cell. The Journal of Physical Chemistry C 2014, 118, 29599-29607.

${ }^{28}$ Hodes, G.; Howell, I. D. J.; Peter, L. M. Nanocrystalline Photoelectrochemical Cells. A New Concept in Photovoltaic Cells. Journal of the Electrochemical Society 1992, 139, 3136-3140.

${ }^{29}$ Bisquert, J. Nanostructured Energy Devices: Equilibrium Concepts and Kinetics; CRC Press: Boca Raton, 2014.

30 Tamm, I.E. Über eine mögliche Art der Elektronenbindung an Kristalloberflächen. Zeitschrift für Physik, 1932, 76, 849-850.

${ }^{31}$ Shockley, W. On the Surface States Associated with a Periodic Potential. Physical Review, 1939, 56, 317-323.

${ }^{32}$ Brillson, L. J. The Structure and Properties of Metal-Semiconductor Interfaces. Surface Science Reports, 1982, 2, 123-326.

${ }^{33}$ Gutierrez, C.; Salvador, P. Mechanisms of Competitive Photoelectrochemical Oxidation of $\mathrm{I}^{-}$and $\mathrm{H}_{2} \mathrm{O}$ at $\mathrm{n}-\mathrm{TiO}_{2}$ Electrodes: A Kinetic Approach. Journal of the Electrochemical Society, 1986, 133, 924-929.

${ }^{34}$ Baranovskii, S. D. Charge Transport in Disordered Solids with Applications to Electronics; Wiley: Weinheim, 2006. 
${ }^{35}$ Kay, A.; Humphry-Baker, R.; Gratzel, M. Artificial Photosynthesis. 2. Investigations on the Mechanism of Photosensitization of Nanocrystalline $\mathrm{TiO}_{2}$ Solar Cells by Chlorophyll Derivatives. The Journal of Physical Chemistry, 1994, 98, 952-959.

${ }^{36}$ Woodruff, D. P.; Delchar, T. A. Modern Techniques of Surface Science; Cambridge University Press: Cambridge, U.K., 1994.

37 Jaegermann, W. The Semiconductor/Electrolyte Interface: A Surface Science Approach. Modern Aspects of Electrochemistry; 1996, 30, 1186.

${ }^{38}$ Bisquert, J.; Zaban, A.; Salvador, P. Analysis of the Mechanisms of Electron Recombination in Nanoporous $\mathrm{TiO}_{2}$ Dye-Sensitized Solar Cells. Nonequilibrium Steady-State Statistics and Interfacial Electron Transfer via Surface States. The Journal of Physical Chemistry B, 2002, 106, 8774-8782.

${ }^{39}$ Kelly, J. J.; Memming, R. The Influence of Surface Recombination and Trapping on the Cathodic Photocurrent at p-Type III-V Electrodes. Journal of the Electrochemical Society, 1982, 192, 730-738.

${ }^{40}$ Shockley, W.; Read, W. T. Statistics of the Recombinations of Holes and Electrons. Physical Review, 1952, 87, 835.

${ }^{41}$ Katz, M. J.; Riha, S. C.; Jeong, N. C.; Martinson, A. B. F.; Farha, O. K.; Hupp, J. T. Toward Solar Fuels: Water Splitting with Sunlight and "Rust"? Coordination Chemistry Reviews, 2012, 256, 2521-2529.

42 Zandi, O.; Hamann, T. W. Enhanced Water Splitting Efficiency Through Selective Surface State Removal. The Journal of Physical Chemistry Letters, 2014, 5, 1522-1526.

${ }^{43}$ Sivula, K. Metal Oxide Photoelectrodes for Solar Fuel Production, Surface Traps, and Catalysis. The Journal of Physical Chemistry Letters, 2013, 4, 1624-1633.

${ }^{44}$ Guijarro, N.; Prevot, M. S.; Sivula, K. Surface Modification of Semiconductor Photoelectrodes. Physical Chemistry Chemical Physics, 2015, 17, 15655-15674.

${ }^{45}$ Langevin, P. Sur la Théorie du Mouvement Brownien Comptes rendus hebdomadaires des séances de l'Académie des sciences (Paris), 1908, 146, 530533.

${ }^{46}$ Auger, P. Sur les Rayons $\beta$ Secondaires Produits dans un Gaz par des Rayons X. Comptes rendus hebdomadaires des séances de l'Académie des sciences (Paris), 1924, 78, 1535-1536.

${ }^{47}$ Credgington, D.; Jamieson, F. C.; Walker, B.; Nguyen, T.-Q.; Durrant, J. R. Quantification of Geminate and Non-Geminate Recombination Losses 
within a Solution-Processed Small-Molecule Bulk Heterojunction Solar Cell. Advanced Materials, 2012, 24, 135-2141.

${ }^{48}$ Li, Z.; Feng, J.; Yan, S.; Zou, Z. Solar Fuel Production: Strategies and New Opportunities with Nanostructures. Nano Today, 2015, 10, 468-486.

${ }^{49}$ Kay, A.; Cesar, I.; Gratzel, M. New Benchmark for Water Photooxidation by Nanostructured $\alpha \mathrm{Fe}_{2} \mathrm{O}_{3}$ Films. Journal of the American Chemical Society, 2006, 128, 15714-15721.

${ }^{50}$ Lin, Y.; Yuan, G.; Sheehan, S.; Zhou, S.; Wang, D. Hematite-Based Solar Water Splitting: Challenges and Opportunities. Energy \& Environmental Science, 2011, 4, 4862-4869.

${ }^{51}$ Shi, X.; Choi, I. Y.; Zhang, K.; Kwon, J.; Kim, D. Y.; Lee, J. K.; Oh, S. H.; Kim, J. K.; Park, J. H. Efficient Photoelectrochemical Hydrogen Production from Bismuth Vanadate-Decorated Tungsten Trioxide Helix Nanostructures. Nature Communications, 2014, 5, 1-8.

${ }^{52}$ Gottesman, R.; Tirosh, S.; Barad, H.-N.; Zaban, A. Direct Imaging of the Recombination/Reduction Sites in Porous $\mathrm{TiO}_{2}$ Electrodes. The Journal of Physical Chemistry Letters, 2013, 4, 2822-2828.

${ }^{53}$ Chatchai, P.; Murakami, Y.; Kishioka, S.-y.; Nosaka, A. Y.; Nosaka, Y. Efficient Photocatalytic Activity of Water Oxidation over $\mathrm{WO}_{3} / \mathrm{BiVO}_{4}$ Composite under Visible Light Irradiation. Electrochimica Acta, 2009, 54, 1147-1152.

${ }^{54}$ Jang, J.-W.; Du, C.; Ye, Y.; Lin, Y.; Yao, X.; Thorne, J.; Liu, E.; McMahon, G.; Zhu, J.; Javey, A.; Guo, J.; Wang, D. Enabling Unassisted Solar Water Splitting by Iron Oxide and Silicon. Nature Communications, 2015, 6, 1-5.

${ }^{55}$ Reichman, J. The Current-Voltage Characteristics of SemiconductorElectrolyte Junction Photovoltaic Cells. Applied Physics Letters, 1980, $36,574-577$.

${ }^{56}$ Gärtner, W. W. Depletion-Layer Photoeffects in Semiconductors. Physical Review, 1959, 116, 84-87.

${ }^{57}$ Tachibana, Y.; Moser, J. E.; Grätzel, M.; Klug, D. R.; Durrant, J. R. Subpicosecond Interfacial Charge Separation in Dye-Sensitized Nanocrystalline Titanium Dioxide Films. The Journal of Physical Chemistry, 1996, 100, 20056-20062.

${ }^{58}$ Bisquert, J.; Fabregat-Santiago, F.; Mora-Seró, I.; Garcia-Belmonte, G.; Giménez, S. Electron Lifetime in Dye-Sensitized Solar Cells: Theory and Interpretation of Measurements. The Journal of Physical Chemistry C, 2009, 113, 1727817290 . 
${ }^{59}$ Bisquert, J. Chemical Capacitance of Nanostructured Semiconductors: Its Origin and Significance for Heterogeneous Solar Cells. Physical Chemistry Chemical Physics, 2003, 5, 5360-5364.

${ }^{60}$ Fabregat-Santiago, F.; Barea, E. M.; Bisquert, J.; Mor, G. K.; Shankar, K.; Grimes, C. A. High Carrier Density and Capacitance in $\mathrm{TiO}_{2} \mathrm{Nan}-$ otube Arrays Induced by Electrochemical Doping. Journal of the American Chemical Society, 2008, 130, 1131211316.

${ }^{61}$ Bisquert, J. Interpretation of Electron Diffusion Coefficient in Organic and Inorganic Semiconductors with Broad Distributions of States. Physical Chemistry Chemical Physics, 2008, 10, 3175-3194.

${ }^{62}$ Sze, S. M. Physics of Semiconductor Devices; 2nd ed.; John Wiley and Sons: New York, 1981.

${ }^{63}$ Bockris, J. O. M.; Mehl, W.; Conway, B. E.; Young, L. Frequency Variation of the cCpacity and Resistance of the Electrical Double Layer at a Metal-Solution Interface. The Journal of Chemical Physics, 1956, 25, 776-777.

${ }^{64}$ Bisquert, J.; Bertoluzzi, L.; Mora-Sero, I.; Garcia-Belmonte, G. Theory of Impedance and Capacitance Spectroscopy of Solar Cells with Dielectric Relaxation, Drift-Diffusion Transport, and Recombination. The Journal of Physical Chemistry C, 2014, 118, 18983-18991. 


\section{сниттв 2 \\ Characterization methods and modeling}

In this chapter we present the main hypotheses and theoretical concepts which underlay the models we have presented in this Thesis. Subsequently, we explain how steady state $j V$ curves are calculated and how IS and CV permit direct assessment of capacitances and the way they can be related to the kinetics and density of states. To illustrate these techniques and explain the fundamental concepts underlying them, we use a simple example, which has been extensively used for the modeling of the $\mathrm{TiO}_{2} /$ electrolyte interface in dye sensitized solar cells. More complex cases will be developed in the rest of this Thesis for semiconductors used for solar fuel production.

\subsection{Modeling framework}

\subsubsection{Hypotheses}

1. In this Thesis all the models that we have developed are based on the resolution of continuity equations for free and trapped carriers (electrons and holes) within the semi-classical approach.

2. Since this Thesis focuses on a kinetic approach to the processes which control photoelectrochemical devices, we can neglect the presence of an electric field, unless specifically mentioned, and Poisson equation is not solved. 
3. Unless specified, we neglect carrier transport and assume carrier concentration to be homogeneous over the whole semiconductor (densities of free and trapped carriers are position independent). This implies that the transport resistance is zero $\left(r_{t}=0\right)$ and that problems related to conductivity or diffusion length limitations will not be treated in this Thesis.

4. We do not consider excitons (which does not affect the conclusions drawn in this Thesis) and trap and surface state energies are not affected when a charged carrier is trapped (no polarons).

5. Interaction between traps or surface states and free carriers is modeled within the multiple-trapping (MT) approach and hopping is neglected.

6. Charge transfer processes at the semiconductor/electrolyte interface are assumed to be of the first order and independent on the energy levels of the donor and the acceptor in the electrolyte (i.e. Marcus theory is not considered).

\subsubsection{Reference model}

From now until the end of chapter 2, we consider the photoanode model depicted in Figure 1.10a, which has been used for the modeling of the $\mathrm{TiO}_{2} /$ electrolyte interface in DSC. ${ }^{1}$ This model will serve as a reference for the rest of this Thesis. In this example, electrons are generated at a rate $G$ in dye molecules and directly injected into the conduction band of $\mathrm{TiO}_{2}$ nanoparticles. Electrons in the conduction band with density $n$ can be trapped (kinetic constant $\beta_{n}$ ) in surface states at the energy level $E_{s s}$ with density $N_{s s}$. Trapped electrons can either be detrapped $\left(\epsilon_{n}\right)$ to the conduction band or transferred to the electrolyte at a rate $k_{s}$. Finally, given the wide band gap of $\mathrm{TiO}_{2}(\sim 3 \mathrm{eV})$, no holes are photogenerated.

As stated by hypothesis (1) in section 2.1.1, the modeling of electronic transport is carried out through the resolution of the continuity equation for free electrons in the conduction band and the master equation for trapped electrons:

$$
\begin{gathered}
\frac{\partial n}{\partial t}=G+\frac{1}{q} \frac{\partial j_{n}}{\partial x}-\beta_{n} n(1-f) N_{s s}+\epsilon_{n} f N_{s s}-k_{c b}\left(n-n_{0}\right) \\
\frac{\partial f}{\partial t}=\beta_{n} n(1-f)-\epsilon_{n} f-k_{s}\left(f-f_{0}\right)
\end{gathered}
$$

where $n_{0}$ and $f_{0}$ are equilibrium quantities, which are connected via the detailed balance, as explained in section 2.1.3. In addition, we consider 
2.1. Modeling framework

the semiconductor/electrolyte interface to be a blocking layer for electrons, so that $j_{n}(L)=0$ and we take $j_{n}(0)=j$. After integrating on the whole semiconductor layer (between 0 and L), Equation 2.1 becomes

$$
\frac{\partial n}{\partial t}=G-\frac{1}{q L} j-\beta_{n} n(1-f) N_{s s}+\epsilon_{n} f N_{s s}-k_{c b}\left(n-n_{0}\right)
$$

\subsubsection{Equilibrium (detailed balance)}

At equilibrium, the detailed balance principle imposes that each individual chemical reaction must balance itself. As explained by Onsager, ${ }^{2}$ "if the dynamical laws of an isolated molecular system are reversible the kinetic theory requires that in the long run every type of motion must occur just as often as its reverse, because the congruence of the two types of motion makes them a priori equivalent. This implies that if we wait a long time so as to make sure of thermodynamic equilibrium, in the end every type of motion is just as likely to occur as its reverse. One consequence of this principle of dynamical reversibility is the condition that when a molecule changes a certain number of times per second from the configuration $A$ to the configuration $B$ the direct reverse transition $B \rightarrow A$ must take place equally often."

Therefore, at equilibrium (in dark, with no applied bias), trapping and detrapping must balance, along with both charge transfer processes. It follows that $n=n_{0}, f=f_{0}$ and, Equation 2.2 becomes:

$$
f_{0}=\frac{1}{1+\frac{\epsilon_{n}}{\beta_{n} n_{0}}}
$$

In addition, trapped electrons are in equilibrium with the conduction band and the surface state occupation probability $f_{0}$ is governed by the Fermi Dirac statistics:

$$
f_{0}=\frac{1}{1+\exp \left(\frac{E_{s s}-E_{F 0}}{k_{B} T}\right)}
$$

Where $E_{F 0}$ is the equilibrium Fermi level. Identifying each term in Equation 2.4 and 2.5, we deduce the relation between the trapping and detrapping kinetics, the surface state energy level and the density of free electrons at equilibrium:

$$
\epsilon_{n}=\beta_{n} n_{0} \exp \left(\frac{E_{s s}-E_{F 0}}{k_{B} T}\right)
$$

Note that equation 2.6 is valid even out of equilibrium. 


\subsubsection{Relation between applied voltage and carrier densities}

For all the models developed in this Thesis, we consider the left contact $(x=0)$ to selectively extract electrons, while the right one $(x=L)$ selectively extracts holes. For such configuration, the applied voltage is generally defined as the difference in quasi Fermi level for electrons $\left(E_{F n}\right)$ and holes $\left(E_{F p}\right):^{3}$

$$
-q V=E_{F n}(0)-E_{F p}(L)
$$

It must be remarked that in the definition of Equation 2.7. forward voltage is negative. For the case of a photoanode used for solar water splitting, hole extraction is performed via a reaction with the electrolyte and does not directly depend on applied voltage, as explained by Salvador. ${ }^{4}$ Therefore, the applied voltage does not modulate the hole Fermi level and its definition is identical to the one established for DSCs:

$$
-q V=E_{F n}(0)-E_{F 0}
$$

It must be pointed out that $E_{F p}$ is directly modulated by photo-generation but indirectly depends on applied volage via recombination, as explained later on in this Thesis.

Finally, it should be emphasized that the density of electrons at the electron selective contact $(n(0))$ can depend on voltage in two ways. In the case of a Schottky barrier, $n(0)$ remains at equilibrium and solely depends on the injection barrier $\Phi_{n}$. In the framework of the Boltzmann approximation it can be written as:

$$
n(0)=n_{0}=N_{c} \exp \left(-\frac{\Phi_{n}}{k_{B} T}\right)
$$

In absence of electric field, $n(0)$ is directly modulated by the applied voltage as:

$$
n(0)=n_{0} \exp \left(-\frac{q V}{k_{B} T}\right)
$$

Unless explicitly mentioned, we will use Equation 2.10 in the rest of this Thesis. Moreover, in the framework of the hypothesis of homogeneity (3), we will impose $n(x)=n(0)=n_{0} \exp \left(-\frac{q V}{k_{B} T}\right)$. 


\subsection{Steady State: $j V$ curve and dc resistance}

In steady state, all variables are independent of time and the time derivatives in Equations 2.2 and 2.3 are zero. The resulting steady state current is obtained:

$$
\bar{j}=q L G-q L\left(k_{s}\left(\bar{f}-f_{0}\right) N_{s s}+k_{c b}\left(\bar{n}-n_{0}\right)\right)
$$

Where the steady state occupation probability of surface states, $\bar{f}$, is:

$$
\bar{f}=\frac{\beta_{n} \bar{n}+k_{s} f_{0}}{\omega_{t}}
$$

With,

$$
\omega_{t}=\beta_{n} \bar{n}+\epsilon_{n}+k_{s}
$$

$\bar{j}$ is a faradic (or resistive) current and is associated to charge transfer from surface states. The current-voltage characteristic of the electrode is depicted in Figure 2.1 .

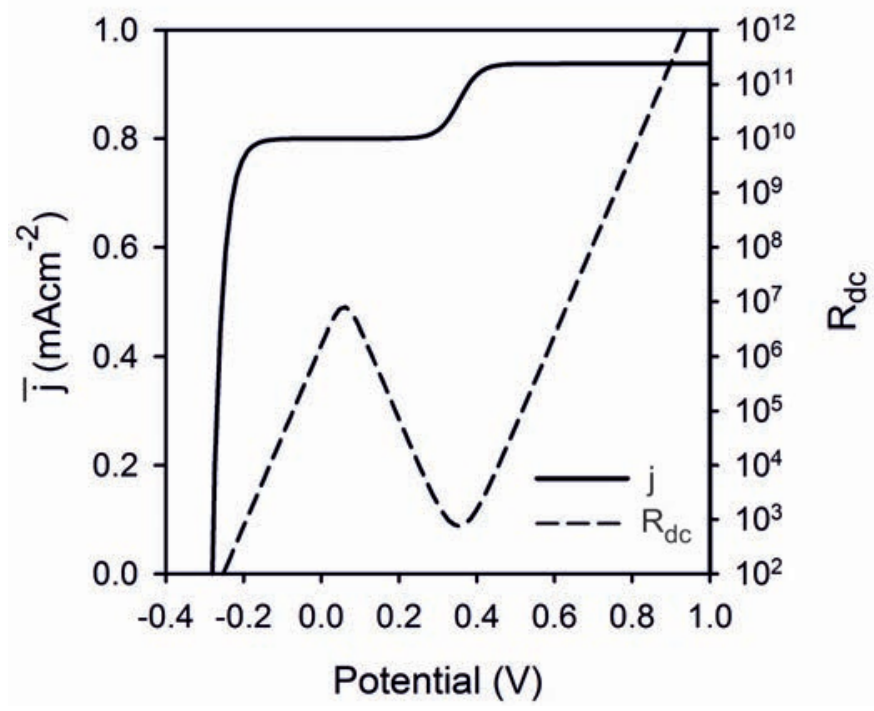

Figure 2.1: $j V$ characteristic plotted from Equations 2.11 and 2.12 (solid line) and corresponding dc resistance $R_{d c}$, obtained from equation 2.14 (dashed line). The parameters chosen for this simulation are $L=1 \mu \mathrm{m}, k_{B} T=26 \mathrm{meV}, G=5 \times 10^{19}$ $\mathrm{cm}^{-3} \mathrm{~s}^{-1}, \beta_{n}=10^{-10} \mathrm{~cm}^{3} \mathrm{~s}^{-1}, n_{0}=10^{15} \mathrm{~cm}^{-3}, N_{s s}=5 \times 10^{20} \mathrm{~cm}^{-3}, k_{s}=0.1 \mathrm{~s}^{-1}$, $k_{c b}=0.1 \mathrm{~s}^{-1}, E_{s s}-E_{F 0}=-0.4 \mathrm{eV}$.

At this point, two remarks should be made on Equation 2.11. First it should be noticed that indirect electron transfer from surface states (second 
term in the right hand side of Equation 2.11) is very similar to the direct electron transfer from the conduction band (third term in the right hand side of Equation 2.11). This example therefore shows that there is no way to distinguish between direct and indirect charge transfer from a single steady state measurement. In addition, it must be emphasized that traps or surface states do not have any effect on photovoltaic performances as long as trapped carriers are not lost in any form (by charge transfer or recombination). In the present case, if $k_{s}=0$, surface states would have no effect on photocurrent, and the total current would simply be given by: $\bar{j}=q L\left(G-k_{c b}\left(\bar{n}-n_{0}\right)\right)$.

Finally, in this example, the dc resistance, $R_{d c}$, of Equation 1.6 is given by:

$$
R_{d c}=\left(\frac{\partial \bar{j}}{\partial V}\right)^{-1}=-q L\left(k_{s} \frac{\partial \bar{f}}{\partial V} N_{s s}+k_{c b} \frac{\partial \bar{n}}{\partial V}\right)
$$

$R_{d c}$ is represented in Figure 2.1 (dashed lines). As such, this resistance does not give any useful information. It is only by applying time dependent methods that the different contributions to $R_{d c}$ will be decoupled, as detailed in the following section.

\section{$2.3 \quad$ Impedance spectroscopy}

IS consists in applying a small perturbation of voltage $\hat{V} \exp (i \omega t)$ to a steady state voltage $\bar{V}$, such that $|\hat{V}|<<|\bar{V}|$. As a result, the corresponding steady state current, $\bar{j}$, is perturbed at first order by an additional quantity $\hat{j} \exp (i \omega t)$, assuming that $|\hat{j}|<<|\bar{j}|$. It is generally convenient to calculate the first order impedance of the perturbed system $Z=\hat{V} / \hat{j}$, which allows connecting physical quantities such as voltage and current, to electrical elements such as resistors and capacitors. To do so, one must write the first order expansion of each variable: $n=\bar{n}+\hat{n} \exp (i \omega t)$, where $\hat{n}=-q \hat{V} /\left(k_{B} T\right) \bar{n}$ (using Equation 2.10), $f=\bar{f}+\hat{f} \exp (i \omega t)$ and $j=\bar{j}+\hat{j} \exp (i \omega t)$. Continuity equations 2.2 and 2.3 are linear and the superposition theorem can be applied. Therefore, after applying Laplace transform to theses equations and performing a first order expansion, these equations become:

$$
\begin{gathered}
i \omega \hat{n}=-\frac{1}{q L} \hat{j}-\beta_{n} \hat{n}(1-\bar{f}) N_{s s}+\left(\beta_{n} \bar{n}+\epsilon_{n}\right) \hat{f} N_{s s} \\
i \omega \hat{f}=\beta_{n} \hat{n}(1-\bar{f})-\left(\beta_{n} \bar{n}+\epsilon_{n}+k_{s}\right) \hat{f}
\end{gathered}
$$


Note that second order terms of the type $\hat{n} \hat{f}$ are neglected. The resulting impedance is derived:

$$
Z(\omega)=-q L\left(i \omega \hat{n}+\beta_{n} \hat{n}(1-\bar{f}) \frac{i \omega+k_{s}}{\beta_{n} \bar{n}+\epsilon_{n}+k_{s}} N_{s s}\right)
$$

For a clearer interpretation of experimental data, it is convenient to represent such impedance in terms of equivalent electrical circuit (EC). To do so, the impedance of the system must be written in terms of capacitances and resistances. Note that there are several possible equivalent circuits for a single impedance expression, and associations of capacitors and resistors can be transformed into inductances in some cases. Here we introduce the chemical capacitance associated to electrons in the conduction band, $C_{\mu}^{c b}$, and in the surface states, $C_{\mu p}^{s s}:{ }^{5}$

$$
\begin{gathered}
C_{\mu}^{c b}=q L \frac{\partial \bar{n}}{\partial V}=\frac{q^{2} L}{k_{B} T} \bar{n} \\
C_{\mu p}^{s s}=\frac{\beta_{n} N_{s s}}{\beta_{n} \bar{n}+\epsilon_{n}}(1-\bar{f}) C_{\mu}^{c b}
\end{gathered}
$$

And the trapping/detrapping and charge transfer resistances from the conduction band and surface states:

$$
\begin{gathered}
\left(R_{t d n}^{s s}\right)^{-1}=\beta_{n} N_{s s}(1-\bar{f}) C_{\mu}^{c b} \\
\left(R_{c t}^{c b}\right)^{-1}=k_{c b} C_{\mu}^{c b} \\
\left(R_{c t}^{s s}\right)^{-1}=k_{s} C_{\mu p}^{s s}
\end{gathered}
$$

Note that the surface state chemical capacitance in equation 2.19 is proportional to the equilibrium chemical capacitance in 1.11. In fact, one can write (neglecting the equilibrium term $k_{s} f_{0}$ in equation 2.12 .

$$
C_{\mu p}^{s s}=B^{-1} C_{\mu}^{s s}
$$

Where,

$$
B=1-\frac{k_{s}}{\omega_{t}}
$$

And

$$
C_{\mu}^{s s}=\frac{q^{2} L}{k_{B} T} \bar{f}(1-\bar{f}) N_{s s}
$$

Using Equations 2.182 .22 , the impedance expression given by Equation 2.17 can be written as:

$$
Z(\omega)=\left(\left(R_{c t}^{c b}\right)^{-1}+i \omega C_{\mu}^{c b}+\frac{1}{R_{t d n}^{s s}+Z_{s s}(\omega)}\right)^{-1}
$$


Where,

$$
Z_{s s}(\omega)=\frac{1}{\left(R_{c t}^{s s}\right)^{-1}+i \omega C_{\mu p}^{s s}}
$$

Equations 2.26 and 2.27 allow for a direct reformulation of the impedance in terms of EC, as shown in Figure $2.2 \mathrm{a}$. In addition, from these equations we deduce that:

$$
R_{d c}=Z(\omega=0)=\left[\left(R_{c t}^{c b}\right)^{-1}+\left(R_{d c}^{s s}\right)^{-1}\right]^{-1}
$$

With,

$$
R_{d c}^{s s}=R_{t d n}^{s s}+R_{c t}^{s s}
$$

(a)

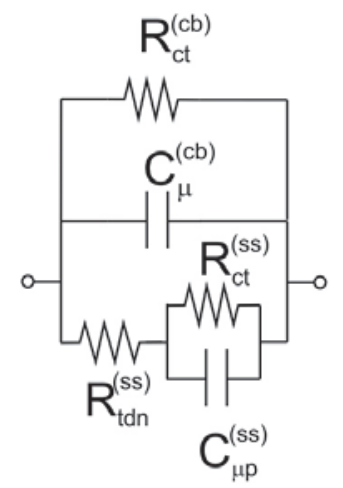

(b)

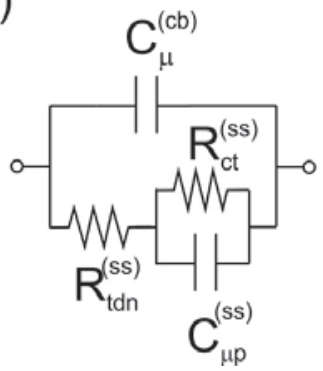

(c)

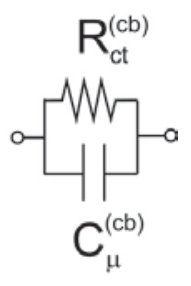

Figure 2.2: (a)EC corresponding to the impedance given in Equations 2.26 and 2.27. (b) Reduced equivalent circuit when the population of trapped electrons prevails over the free electron population and two processes govern IS response: trapping/detrapping of electrons and indirect charge transfer from surface states. (c) Reduced equivalent circuit when the population of free electrons in the conduction band prevails over the one of trapped electrons and only charge transfer from the conduction band can be observed. 
Note that in the case of DSCs, one may take into account charge transfer from the exponential density of surface states in $\mathrm{TiO}_{2}$ (Figure 1.6 $\mathrm{a}$ ), along with the Marcus charge transfer rates given in Equations 1.4a and $1.4 \mathrm{~b}$. In this case, $R_{d c}$ (generally noted $R_{\text {rec }}$ in the literature of DSC) reads $R_{d c}=R_{0} \exp \left(-q \beta V /\left(k_{B} T\right)\right)$, where $\beta$ is such that $\frac{1}{2}<\beta \leq 1 .^{6} \quad \beta$ takes the value 1 when recombination occurs exclusively with electrons from the conduction band, while it takes the value $\frac{1}{2}$, when only electrons which have been trapped in the exponential DOS of $\mathrm{TiO}_{2}$ recombine with the electrolyte. ${ }^{7}$

Equations 2.28 and 2.29 show that IS allows distinguishing the various faradic contributions to steady state current. In particular, these equations state that indirect charge transfer from surface states can compete with direct electron transfer from the conduction band (i.e $R_{d c}^{s s}<<R_{c t}^{c b}$ ) only if both, trapping/detrapping and transfer of electrons, are fast since both processes are in series. In Figure 2.3a, the contributions of direct and indirect charge transfer to the steady state current (Equation 2.11) are shown. Besides, the information provided by the chemical capacitance associated to the conduction band (Equation 2.18) and surface states (Equation 2.19) allow extracting the kinetics associated to each process and the density of surface states. Both capacitances are represented in Figure $2.3 \mathrm{~b}$ in logarithmic scale. As expected, $C_{\mu}^{c b}$ follows the exponential Boltzmann distribution while $C_{\mu p}^{s s}$ displays the peak behavior of Figure $1.10 \mathrm{a}$.

We shall also remark that within the quasistatic approximation $(\omega \rightarrow$ $0),{ }^{8}$ the impedance of Equation 2.26 is reduced to:

$$
Z(\omega) \approx \frac{R_{d c}}{1+i \omega \tau_{n}}
$$

Where $R_{d c}$ has been defined in Equation 2.28 and $\tau_{n}$ is the electron lifetime defined as $\tau_{n}=R_{d c} C_{l f}$, with: ${ }^{9}$

$$
C_{l f}=C_{\mu}^{c b}+B C_{\mu}^{s s}
$$

$C_{\mu}^{c b}, B$ and $C_{\mu}^{s s}$ being respectively defined by Equations 2.18, 2.24 and 2.25 . IS measurements are usually represented in terms of complex plane plots where the imaginary part of the measured impedance is represented as a function of its real part. In this representation the resulting patterns are semicircles. For each semicircle one capacitance and one resistance values can be extracted by fitting of the impedance spectra with the proper EC. In the present example, a maximum of two semicircles can be observed in the complex plane, as shown in Figure 2.4. 

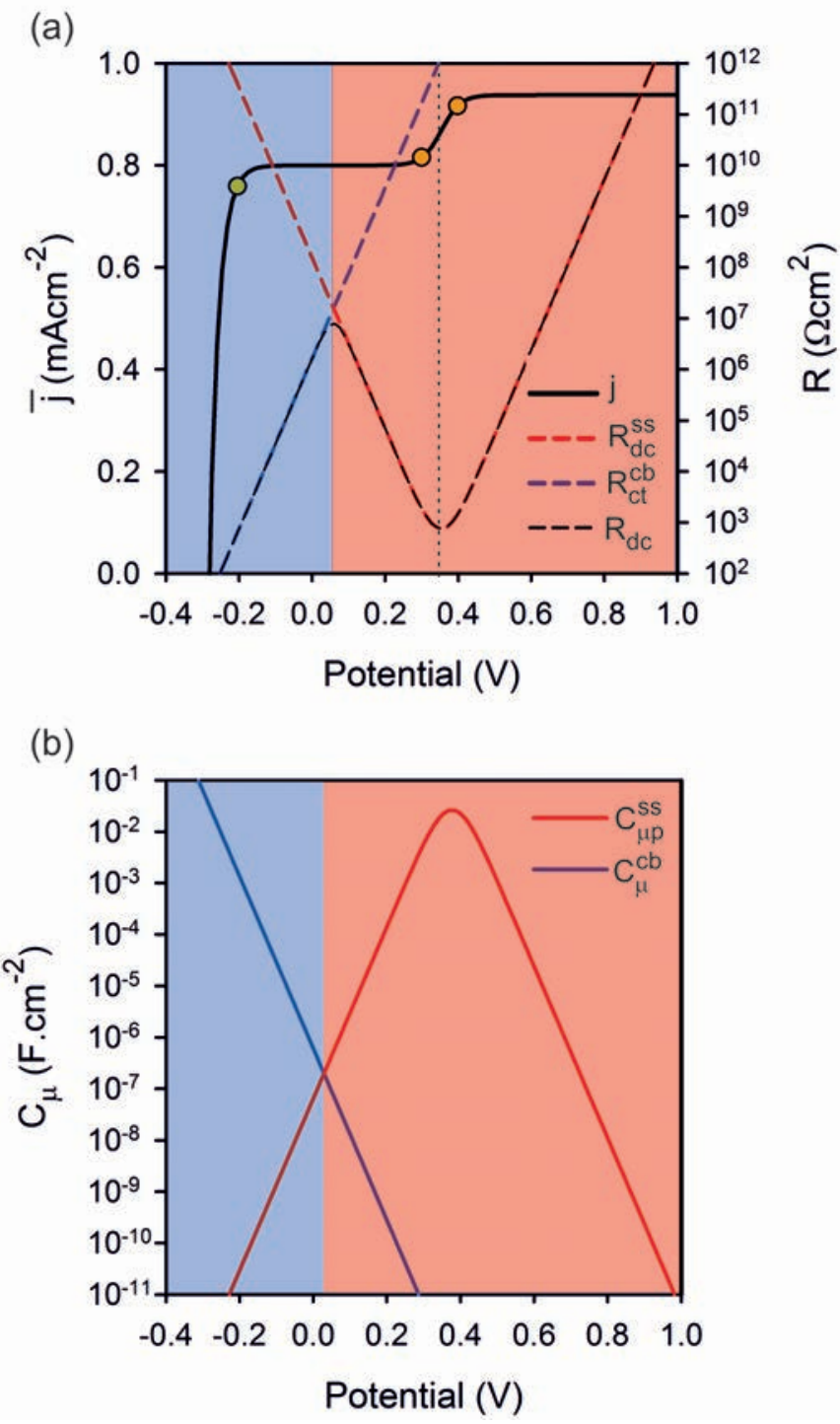

Figure 2.3: (a)Logarithmic plot of the different faradic contributions which control the steady state current-voltage characteristic and dc resistance $\mathrm{R}_{d c}$, plotted in Figure 2.1. There are two faradic processes which control steady state: direct charge transfer of electrons from the conduction band to the electrolyte with resistance $\mathrm{R}_{c t}^{c b}$, and trapping/detrapping $\left(\mathrm{R}_{t d n}^{s s}\right)$ in series with charge transfer from surface states $\left(\mathrm{R}_{c t}^{s s}\right)\left(R_{d c}^{s s}=R_{c t}^{s s}+R_{t d n}^{s s}\right)$. The dotted line indicates the correspondence between the minimum of $\mathrm{R}_{d c}^{s s}$ and the inflection point in the $j V$ characteristic. The orange dots indicate the points of the $j V$ characteristic at which the complex plane plots of Figure 2.4 have been simulated. (b) Corresponding chemical capacitances. 
(a)

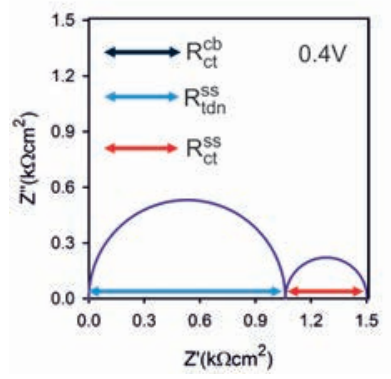

(b)

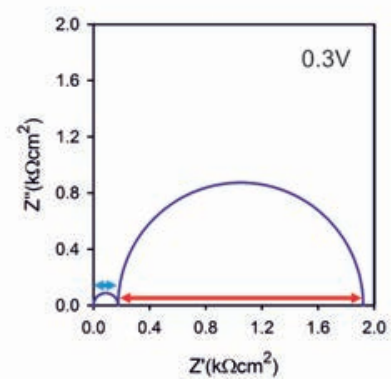

(c)

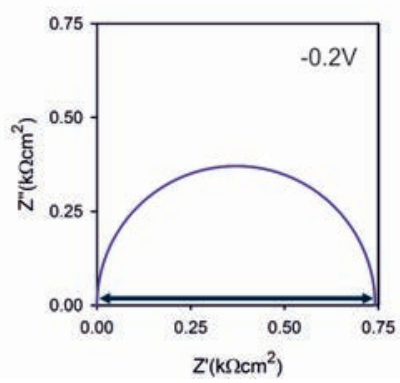

Figure 2.4: Complex plane impedance spectra calculated for the steady state point of Figure 2.3 (orange dots). In cases (a) and (b), the population of free electrons is negligible with respect to the one of trapped electrons and the impedance spectra is featured by two arcs. The low frequency arc corresponds to indirect charge transfer from surface states $\left(R_{c t}^{s s}\right)$ while the second one arises from the trapping detrapping process $\left(R_{t d n}^{s s}\right)$. In both cases, the EC of Figure $2.2 \mathrm{p}$ can be used to fit this type of IS spectra. In (c), the applied potential is such that the population of free electrons is much superior to the one of trapped electrons and the impedance spectra is featured by one single arc associated to direct charge transfer of electrons from the conduction band. In this case, the EC of Figure 2.2 r can be used to fit this spectrum.

In order to identify the process associated to each arc, it is important to simplify the EC in order to avoid over-parametrization of the system. In the case where two arcs are observed, a maximum of two resistance and two capacitance values can be obtained, while the EC of Figure 2.2 contains three resistors. For the cases depicted in Figure 2.4a,b, the applied voltage is positive enough to neglect direct charge transfer of free electrons from the conduction band to the electrolyte, and we have $R_{c t}^{c b} \rightarrow \infty$. The simplified EC, which serves to fit the IS spectra of Figure 2.4 $\mathrm{a}, \mathrm{b}$ is therefore the one depicted in Figure 2.2 b. From this circuit, we deduce that the low frequency arc is associated to charge transfer from surface states, while the high frequency one is associated to trapping/detrapping of electrons from the conduction band to the surface states. For the case of Figure 2.4c, there is only one arc and the circuit must be simplified into a $R C$ circuit. Since voltage is cathodic and the density of electrons in the conduction band is much larger than the trapped electron density, it follows that $R_{c t}^{c b}<<$ $R_{c t}^{s s}+R_{t d n}^{s s}$ and the simplified EC is the one of Figure 2.2.

However, it should be pointed out that the EC approach presents two main issues. Firstly, we should recall that IS is a two contact measurement so that the information of different internal loci in the sample may be lumped into a single EC element. Secondly, the expression of a given 
impedance model may be interpreted in terms of several equivalent circuit representations. In order to tackle both issues it is therefore necessary to perform further experiments and verify the physical meaning of the extracted parameters. One possibility consists in plotting the voltage variations of the capacitances and resistances obtained with a given EC, as in Figure 2.3

Note that in the literature, full numerical resolution of transport and charge transfer equations is sometimes performed for the interpretation of IS spectra. The advantage of this other approach is that it allows taking into account more features and is certainly more accurate than the analytical approach. However, as any experimental technique, IS interpretation is limited by the amount of information one can extract from the experimental data. The equivalent circuit is therefore an excellent tool to discriminate between the main dominant features that can be experimentally unveiled.

\subsection{Cyclic voltammetry}

CV consists in measuring the electric current generated when applying a ramp of potential at a given scan rate, $\nu$, departing from potential $V_{0}$ and reaching potential $V_{1}$ after a time $t_{1}\left(V_{1}=V_{0}-\nu t_{1}\right)$. The reverse ramp is subsequently applied at a rate $-\nu$ from $V_{1}$ to $V_{0}$. In other words:

$$
\begin{aligned}
& V\left(t \leq t_{1}\right)=V_{0}-\nu t \\
& V\left(t \geq t_{1}\right)=V_{1}+\nu t
\end{aligned}
$$

Note that sometimes, the potential at which CV is started does not coincide with the potential at which it ends. In such measurements, the voltage sweep does not leave time to all faradic processes to occur during the scan and charges are accumulated within the semiconductor, which induces a capacitive current. Higher scan rates induce larger capacitive currents. The current in CV measurements can therefore be written as the contribution of the faradic and the capacitive current. For the present example, the total current can be written as:

$$
j(t)=\underbrace{-q L\left(\frac{\partial n}{\partial t}+\frac{\partial f}{\partial t} N_{s s}\right)}_{\text {capacitive current }}+\underbrace{\bar{j}}_{\text {faradic current }}
$$

Where $\bar{j}$ is given by Equation 2.11. Usually, faradic processes partially hide the capacitive ones. In order to analyze capacitive features, it is consequently useful to limit faradic processes by using inert electrolyte and 
avoiding electron-hole recombination by performing measurements in dark. This is why CV measurements are delicate and limited in terms of working conditions.

Using Equations 2.32 and 2.33 for the definition of the voltage and neglecting faradic contributions, Equation 2.34 can be written with chemical capacitances:

$$
j(t)= \pm\left(C_{\mu}^{c b}+C_{\mu}^{s s}\right) \nu
$$

Where the sign - stands for a voltage sweep in the cathodic direction (Equation 2.32) and the sign + for a sweep in the anodic direction (Equation 2.33). Note that the chemical capacitances which appear in Equation 2.35 are defined for a large voltage perturbation and are not necessarily equal to the one obtained through small perturbation techniques such as IS.

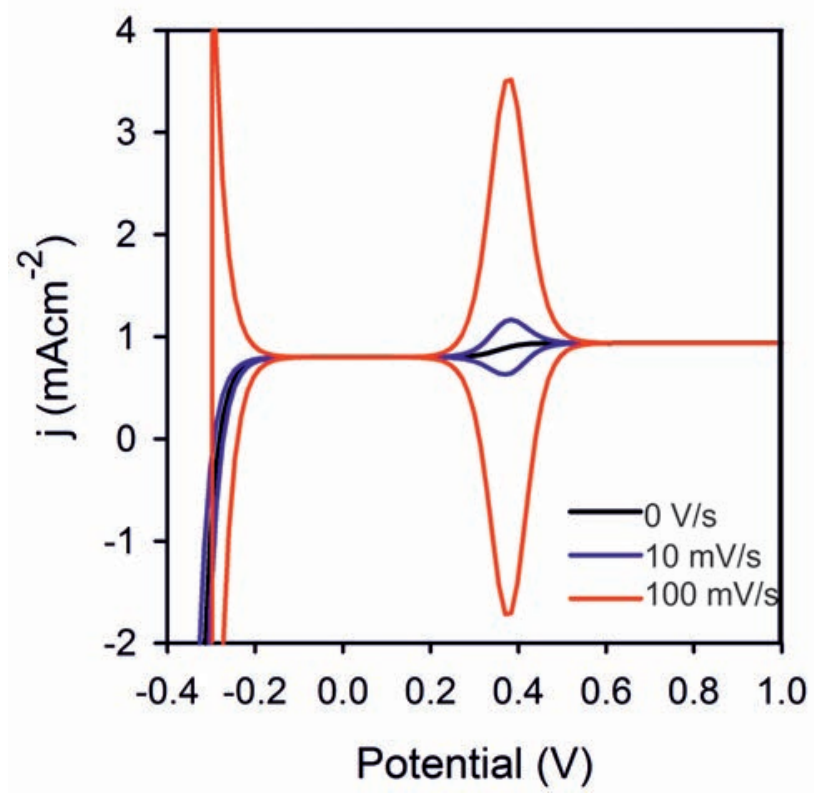

Figure 2.5: Simulations of the $C V$ pattern corresponding to the chemical capacitance and faradic contributions depicted in Figure 2.3 for three different scan rates. When $\nu=0$, the CV corresponds to the steady state $j V$ curve represented in Figures 2.1 and 2.3 and the origin of the current is purely faradic. For the case $\nu=10$ $\mathrm{mV} / \mathrm{s}$, the capacitive feature associated to surface states can be observed but the one associated to the conduction band is hidden by the faradic current. Finally, for $\nu=100 \mathrm{mV} / \mathrm{s}$, the current is purely capacitive and both capacitive contributions from surface states and conduction band can be observed. 
In Figure 2.5, we give a simulation of the CV response for the example treated here, in the case where the chemical capacitances of Equation 2.35 are the one obtained by IS (Equations 2.18 and 2.19). This example shows that the capacitive feature can be hidden by the faradic contribution (at low scan rate). For larger scan rates, the capacitive contribution prevails and one can observe the peak behavior associated to the surface state capacitance at anodic applied bias (around 0.4 V), and the exponential behavior associated to the chemical capacitance of the conduction band at cathodic bias.

A solid framework has already been proposed by Fabregat et al. ${ }^{10}$ in order to analyze the capacitive features observed in CV measurements at the semiconductor/electrolyte interface. However in their study, the main assumption is that the capacitance obtained by $\mathrm{CV}$ is the same as the one obtained by IS (as in the example of Figure 2.5). In addition, if the faradic component cannot be clearly identified and quantified, it is not feasible to obtain kinetic information and only density of states can be recovered from the chemical capacitance. Hence, there is still room for improvement for the characterization of the semiconductor/electrolyte interface by CV. In Chapters 5 and 6 , this point will be further explained and a new theory of CV including non equilibrium effects due to fast scan rates will be presented.

Finally, we should comment on the advantages and drawbacks of both, IS and CV techniques. The first one allows obtaining accurate results but measurements usually take a few hours, and samples may undergo degradation meanwhile, especially under continuous illumination. But the main problem of IS is the amount of efforts required for the analysis of experimental results. On the contrary, CV allows a swift analysis of the faradic and capacitive processes, but the degree of characterization of charge transfer processes at the semiconductor/electrolyte interface is usually more limited than what can be achieved with IS.

\subsection{References}

${ }^{1}$ Bisquert, J. Theory of the Impedance of Charge Transfer via Surface States in Dye-Sensitized Solar Cells. Journal of Electroanalytical Chemistry, 2010, 646, 43-51.

${ }^{2}$ Onsager, L. Reciprocal Relation in Irreversible Processes. I. Physical Review, 1931, 37, 405.

${ }^{3}$ Bisquert , J.; Garcia-Belmonte, G. On Voltage, Photovoltage, and Photocurrent in Bulk Heterojunction Organic Solar Cells. The Journal of Physical Chemistry Letters, 2011, 2, 1950-1964. 
${ }^{4}$ Salvador, P. Semiconductors' Photoelectrochemistry: A Kinetic and Termodynamic Analysis in the Light of Equilibrium and Nonequilibrium Models. The Journal of Physical Chemistry B, 2001, 105, 6128-6141.

${ }^{5}$ Bisquert, J. Chemical Capacitance of Nanostructured Semiconductors: Its Origin and Significance for Heterogeneous Solar Cells. Physical Chemistry Chemical Physics, 2003, 5, 5360-5364.

${ }^{6}$ Bisquert, J. ; Zaban, A.; Greenshtein, M.; Mora-Seró, I. Determination of Rate Constants for Charge Transfer and the Distribution of Semiconductor and Electrolyte Electronic Energy Levels in Dye-Sensitized Solar Cells by Open-Circuit Photovoltage Decay Method. Journal of the American Chemical Society, 2004, 126, 13550.

${ }^{7}$ Ansari-Rad, M.; Abdi, Y.; Arzi, E. Reaction Order and Ideality Factor in Dye-Sensitized Nanocrystalline Solar Cells: A Theoretical Investigation. The Journal of Physical Chemistry C, 2012, 116, 10867-10872.

${ }^{8}$ Bisquert, J. Beyond the Quasi-Static Approximation: Impedance and Capacitance of an Exponential Distribution of Traps.Physical Review B, 2008, 77, 235203.

${ }^{9}$ Bisquert, J.; Fabregat-Santiago, F.; Mora-Seró, I.; Garcia-Belmonte, G.; Giménez, S. Electron Lifetime in Dye-Sensitized Solar Cells: Theory and Interpretation of Measurements. The Journal of Physical Chemistry $C$, 2009, 113, 17278-17290.

${ }^{10}$ Fabregat-Santiago, F.; Mora-Seró, I.; Garcia-Belmonte, G.; Bisquert, J. Cyclic voltammetry studies of nanoporous semiconductor electrodes. Models and application to nanocrystalline $\mathrm{TiO}_{2}$ in aqueous electrolyte. The Journal of Physical Chemistry B, 2003, 107, 758-769. 



\section{Publication 1}

\subsection{Candidate's contribution}

In the case of Chapter 3, the nature and extent of my contribution to the work was the following:

Nature of contribution

Extent of contribution

- Review of existing literature and assessment on the present understanding of device physics in photoelectrochemical devices.

$25 \%$

- Verification of all equations

- Help in the preparation of manuscript drafts.

\subsection{Published manuscript}

DOI: http://dx.doi.org/10.1021/jz402703d 


\section{Publication 2}

\subsection{Candidate's contribution}

In the case of Chapter 4 , the nature and extent of my contribution to the work was the following:

\section{Nature of contribution}

- Review of existing literature and assessment on the present understanding of device physics in photoelectrochemical solar cells.

- Developed all model equations.

- Performed simulations.

- Wrote manuscript drafts.

- Edited the manuscript in accordance with the comments provided by co-author and referees.

- Wrote the first draft for the reply to referees.

\subsection{Published manuscript}

DOI: http://dx.doi.org/10.1021/jz3010909 


\section{Publication 3}

\subsection{Candidate's contribution}

In the case of Chapter 5, the nature and extent of my contribution to the work was the following:

\section{Nature of contribution}

- Reviewed existing literature and assessment on the present understanding of $\mathrm{CV}$ for semiconductor/electrolyte interface characterization.

- Developed all model equations.

- Performed simulations.

- Designed experiments.

- Analyzed and discussed experimental data.

- Discussed validity of the theoretical model.

- Wrote manuscript drafts.

- Edited the manuscript in accordance with the comments provided by co-authors and referees.

- Wrote the first draft for the reply to referees.

\subsection{Published Manuscript}

DOI: http://dx.doi.org/10.1021/jz400573t 


\section{구의 6}

\section{Publication 4}

\subsection{Candidate's contribution}

In the case of Chapter 6, the nature and extent of my contribution to the work was the following:

Nature of contribution

Extent of contribution

- Reviewed existing literature and assessment on the present understanding of the $\mathrm{TiO}_{2} /$ electrolyte interface.

- Developed all model equations.

- Performed simulations.

- Designed experiments.

- Analyzed, fitted and discussed experimental data.

- Discussed validity of the theoretical model.

- Wrote manuscript drafts.

- Edited the manuscript in accordance with the comments provided by co-authors and referees.

- Wrote the first draft for the reply to referees.

\subsection{Published Manuscript}

DOI: http://dx.doi.org/10.1021/jz4027584 


\section{CHAPTER \\ Publication 5}

\subsection{Candidate's contribution}

In the case of Chapter 7, the nature and extent of my contribution to the work was the following:

\section{Nature of contribution}

- Review of existing literature and assessment on the present understanding of trap assisted processes in device physics.

- Developed $70 \%$ of model equations.

- Performed simulations.

- Wrote manuscript drafts.

- Edited the manuscript in accordance with the comments provided by co-authors and referees.

- Wrote the first draft for the reply to referees.

7.2 Published Manuscript

DOI: http://dx.doi.org/10.1021/jp411004e 


\section{спитет 8 \\ Publication 6}

\subsection{Candidate's contribution}

In the case of Chapter 8 , the nature and extent of my contribution to the work was the following:

Nature of contribution

Extent of contribution

- Reviewed existing literature and assessment on the present understanding of device physics in photoelectrochemical solar cells.

- Developed all model equations.

- Performed $50 \%$ of the simulations.

- Discussed the validity of the theoretical model.

- Compared predictions of the model with experimental data from the literature.

- Wrote manuscript drafts.

- Edited the manuscript in accordance with the comments provided by co-authors and referees.

- Went through the whole publication submission process

\subsection{Published Manuscript \\ DOI: http://dx.doi.org/10.1039/C5TA03210E}




\section{СНАРтвR 9}

\section{Discussion of the results}

In this chapter we show how the objectives proposed in section 1.3 .2 have been fulfilled, in light of the results obtained in the publications of Chapters 4 to 8 . Note that we have laid the basis of this Thesis in Chapter 3 by establishing the correspondence between electrochemical and physical quantities relative to the energy diagram of the semiconductor/electrolyte interface.

Investigation on the origin of the photocurrent in devices used for solar fuel production was carried out in Chapters 4 and 8 . On the one hand, we have established a general and complete electrical equivalent circuit, including all the necessary features for the analysis of the charge transfer and recombination kinetics at the semiconductor/electrolyte interface. In particular, two new features are integrated in this equivalent circuit: the chemical capacitance and hole transfer resistance, both associated to the valence band. This circuit was reduced to two important cases in order to determine the prevailing processes controlling photocurrent at low applied bias. The first one corresponds to trapping detrapping of electrons and holes and indirect hole transfer from surface states, while the other one represents bulk recombination and direct hole transfer from the valence band. Both corresponding equivalent circuits were shown to be identical. However, by analyzing the low frequency capacitance, it is possible to distinguish between both charge transfer processes. If the low frequency capacitance displays a peak behavior with voltage, indirect charge transfer dominates photocurrent at low applied voltage. On the contrary, if saturation of this capacitance is observed, direct hole transfer prevails. This model has proven to be a powerful tool for the analysis of a number of cases taken from the literature. In fact, the equivalent circuit developed in this Thesis has allowed determining in situ the nature of the photocurrent for different materials, electrolytes and experimental conditions. 
The study of the role of surface states on the photocurrent production has been performed through Chapters 4 and 8 . In those chapters, we have demonstrated that at low applied voltage bias, surface states can either act as recombination centers or as intermediaries for charge transfer, depending on the kinetics of trapping/detrapping of electrons, and hole transfer. If hole transfer kinetics is much faster than the one of electron trapping/detrapping, surface states can have beneficial effect for photocurrent production, while in the opposite case, such states are responsible for current losses. However, hole trapping/detrapping kinetics has very little effect at low applied bias. In addition, through drift diffusion simulations, we have shown that the presence of an electric field allows separating charges at the semiconductor/electrolyte interface and charge assisted recombination is reduced. It follows that in presence of a space charge region substantial, hole charge transfer from surface states can occur, contrary to the predictions of classical models.

The nature of the surface states which affect the semiconductor/ electrolyte interface has been under scrutiny for the case of hematite, in Chapter 5. and more generally discussed in Chapter 8. Through CV measurements, it has been shown that the capacitive feature associated to the surface states of $\mathrm{Fe}_{2} \mathrm{O}_{3}$ is intimately related to the applied voltage and illumination level. In particular, under prolonged anodic applied bias or illumination, a large surface state capacitive response has been observed, which vanishes in dark condition at zero applied bias. These experiments confirm the extrinsic nature of the surface states of $\mathrm{Fe}_{2} \mathrm{O}_{3}$. However, as commented in Chapter 8 , the nature of the surface states strongly depends on the nature of the semiconductor/ electrolyte interface. In particular, when using atomic layer deposition method, varying the annealing temperature, the nature of the electrolyte or its $\mathrm{pH}$, such capacitive feature can disappear from the CV pattern or new species can be created. In addition, combining experimental CV data with a simple analytical model, it has been shown that if the capacitive response in CV measurements is featured by one single peak when sweeping voltage in the cathodic direction, surface states are close to the valence band and act as recombination centers. This is the case of the $\mathrm{Fe}_{2} \mathrm{O}_{3} /$ electrolyte interface. In this case, the capacitance value depends on scan rate and the capacitive current is not proportional to scan rate. On the contrary, two symmetric capacitive peaks in CV patterns indicate the presence of surface states close to the conduction band. Electrons which are trapped in such states have time to equilibrate with the conduction band and are less likely to recombine with trapped holes. In such configuration, the capacitance is independent of scan rate while the capacitive current is proportional to scan rate. Finally, thanks to the developed model, the cat- 
alyzing effect of a layer of iridium oxide $\left(\mathrm{IrO}_{x}\right)$ on the hole transfer reaction has been verified. In fact, the apparition of two symmetric peaks in the CV pattern of the $\mathrm{Fe}_{2} \mathrm{O}_{3} / \mathrm{IrO}_{x}$ /electrolyte interface reveals the presence of new states, induced by the presence of the $\mathrm{IrO}_{x}$ layer, close to the hematite conduction band. Such states reduce electron/hole recombination and favor hole transfer to the electrolyte.

The analysis of the effect of the semiconductor morphology on photoelectrochemical performance has been investigated in Chapters 6 and 7 . On the first hand, it was demonstrated that the size of $\mathrm{TiO}_{2}$ nanoparticles strongly influences the density of states of such material. To achieve this result, two types of particles have been synthesized: nanoparticles (P25), whose diameter was of the order of 20-25 nm, and submicron particles, with a diameter of 200-250 nm. By combining CV measurements with a simple kinetic model, we have been able to unveil morphology dependent features of the density of states. For both, the P25 and submicron particles, an exponential DOS has been measured. However an additional mono-energetic density of deep states has been detected for the submicron particles. In addition, the trapping/detrapping kinetics have been extracted via CV measurements for the first time, and have been shown to be faster in the case of P25 nanoparticles than for the submicron particles. On the other hand, an impedance spectroscopy model has been developed for the analysis of the bulk recombination kinetics. The general electrical equivalent circuit model, initially developed by Sah, includes bulk trap states along with free electrons and holes. Such circuit has been reduced to well known simplified examples (dark equilibrium, initially developed by Shockley, and doped semiconductors). Moreover, the analysis of two important physical cases has also been proposed. Firstly, in the case of band to band recombination (without trap states), the complex plane is featured by one single arc. Secondly, in presence of a large density of bulk trap states, two arcs can be detected. In fact, when the trap chemical capacitance is much larger than the one of free carriers, processes of accumulation of charges in the conduction and valence bands can be decoupled. Consequently, both arcs correspond to the chemical capacitance of electrons and holes, and can be neatly distinguished in the case of doped semiconductors since the difference between the majority and minority carrier capacitances is large (unlike intrinsic semiconductors). In such case, the kinetics of trapping/detrapping of electrons and holes can be recovered. This analysis represents an important contribution for the analysis of the recombination kinetics in semiconductor films where bulk recombination can affect charge transfer at the semiconductor/electrolyte interface. 
In summary, the results obtained in this Thesis provide new and important insights on the characterization of the charge transfer processes at the semiconductor/electrolyte interface. As explained in the introduction (Chapter 1), three types of optimization methods are generally applied in order to enhance charge transfer kinetics at such interface: (i) design of multiple junction devices, (ii) use of catalayst and/or passivating layers, and (iii) photoelectrode nanostructuration. However, all these methods rely on the clear identification of the limiting charge transfer mechanism. With the tools developped during this $\mathrm{PhD}$, a quantitative assessment of recombination processes which limit solar fuel production is now possible. In addition, the new techniques proposed in these studies allow tracking in situ the evolution of the density of traps and surface states and their influence on charge transfer at the semiconductor/electrolyte interface, when modifying the morphology of the photoelectrode or when changing the nature or composition of the electrolyte. Moreover, this whole body of works has important implications for stability studies since one can also analyze in operando the evolution of the photoelectrochemical processes which affect the semiconductor/electrolyte interface during degradation. Finally, a recent and important analysis by $\mathrm{Hu}$ and coworkers ${ }^{1}$ should be mentioned here. These authors have in fact demonstrated the utility of the approaches previously summarized. By combining the impedance method proposed in this Thesis with XPS analysis, they have shown that the density of iron surface states, which promote water photo-oxidation, is reduced under oxygen treatment, which induces photocurrent losses.

\section{References}

${ }^{1} \mathrm{Hu}$, Y.; Boudoire, F.; Hermann-Geppert, I.; Bogdanoff, P.; Tsekouras, G.; Mun, B. S.; Fortunato, G.; Graetzel, M.; Braun, A. Molecular Origin and Electrochemical Influence of Capacitive Surface States on Iron Oxide Photoanodes. The Journal of Physical Chemistry C, 2016, 120, 32503258 . 


\section{CHAPTER 10}

\section{Conclusiones y futuras líneas de investigación}

En este capítulo se resumen las principales conclusiones extraídas de lo seis artículos de investigación presentados en esta Tesis Doctoral y publicados en revistas científicas internacionales.

- Se han presentado un conjunto de relaciones entre las cantidades físicas y electroquímicas relativas a la interfase semiconductor/ electrolito.

-Se ha desarrollado un circuito equivalente que captura las características principales de la cinética de recombinación y transferencia de carga.

- Se ha demostrado que las transferencias directa e indirecta se pueden distinguir gracias a la capacidad de baja frecuencia de dicho circuito.

-Se han simulado casos cineticos en los cuales los estados superficiales pueden ser beneficiosos en términos de actividad foto-electroquímica.

- Se ha propuesto un modelo analítico de voltametría cíclica que permite evaluar si un estado superficial es un centro de recombinación.

- Mediante voltametría cíclica, se ha confirmado el carácter extrínseco de los estados superficiales de la hematita.

- Se ha observado que la densidad de estados y la cinética de atrapamiento en tales estados varian al cambiar la morfología del $\mathrm{TiO}_{2}$.

-Se han analizado los espectros de impedancia para extraer la cinética de un sistema con recombinación interna banda a banda y mediante trampas. 
En resumen, la presente Tesis Doctoral ha permitido desarrollar herramientas de caracterización muy importantes en el estudio de los procesos de transferencia de carga a la interfase semiconductor/electrolito. Los resultados obtenidos constituyen una base sólida para futuras líneas de investigación, tal como se detalla a continuación.

En primer lugar, se podrían integrar efectos electrostáticos en las herramientas desarrolladas en esta Tesis Doctoral. En efecto, la influencia del campo eléctrico en la zona de carga espacial se ha considerado únicamente para simulaciones por conducción y difusión en régimen estacionario, y sin tener en cuenta la carga atrapada. Sin embargo, cabe destacar que el desplazamiento de bandas inducido por una alta densidad de cargas atrapadas presenta un papel importante sobre la transferencia de carga en la interfase semiconductor/electrolito. Además, la capacidad química de los estados superficiales puede estar afectada por dicho desplazamiento de banda. En este caso, los valores de los parámetros cinéticos y de las densidades de estados, extraídos de medidas capacitivas, deberían incluir correcciones electrostáticas.

En segundo lugar, en esta Tesis se ha considerado únicamente la unión semiconductor/electrolito. Sin embargo, se podrían extender estos trabajos a sistemas más complejos y eficientes, tales como uniones múltiples con sistemas fotovoltaicos acoplados y/o catalizadores. De particular importancia es el efecto del fotovoltaje y de la fotocorriente, producidos por células solares, sobre la transferencia de carga en la interfase semiconductor/electrolito, así como la interacción entre capas catalizadoras y los estados superficiales.

En tercer y último lugar, las herramientas de caracterización desarrolladas en estos estudios podrían ser muy útiles para estudiar la estabilidad de otros sistemas fotovoltaicos como las células solares de perovskita. En efecto, se ha demostrado que estas células son muy sensibles al ambiente externo (presencia de oxígeno y/o humedad). Consecuentemente, se podrían utilizar y extender los métodos de análisis capacitivos empleados en la Tesis para estudiar la formación de defectos en este tipo de células, a lo largo del proceso de degradación. Así mismo, se podría concluir sobre la influencia de las trampas en la degradación de la perovskita. 